\title{
The Role of Individual Carbohydrate-Binding Sites in the Function of the Potent Anti-HIV Lectin Griffithsin
}

\author{
Jie Xue, ${ }^{\dagger}$ Yongguang Gao, ${ }^{\dagger, \ddagger}$ Bart Hoorelbeke, ${ }^{\S}$ Ioannis Kagiampakis, ${ }^{\dagger}$ Bo Zhao, ${ }^{\dagger}$ Borries Demeler,, \\ Jan Balzarini, ${ }^{\$}$ and Patricia J. LiWang, ${ }^{* \dagger}$ \\ ${ }^{\dagger}$ University of California Merced, 5200 North Lake Road, Merced, California 95343, United States \\ ${ }^{\S}$ Rega Institute for Medical Research, KU Leuven, Minderbroedersstraat 10, B-3000 Leuven, Belgium \\ "The University of Texas Health Science Center at San Antonio, Department of Biochemistry, MC 7760, 7703 Floyd Curl Drive, San \\ Antonio, Texas 78229-3901, United States
}

\section{Supporting Information}

\begin{abstract}
Griffithsin (GRFT) is a lectin that has been shown to inhibit HIV infection by binding to high mannose glycan structures on the surface of gp120, and it is among the most potent HIV entry inhibitors reported so far. However, important biochemical details on the antiviral mechanism of GRFT action remain unexplored. In order to understand the role of the three individual carbohydrate-binding sites (CBS) in GRFT, mutations were made at each site (D30A, D70A, and D112A), and the resulting mutants were investigated. NMR studies revealed that each GRFT variant was folded but showed significant peak movement on the carbohydrate-binding face of the protein. The wild-type and each point mutant protein appeared as tight

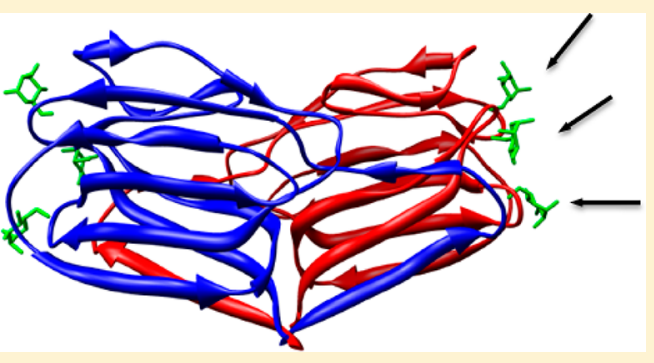
dimers with a $K_{\mathrm{d}}$ below $4.2 \mu \mathrm{M}$. Mutation of any individual CBS on GRFT reduced binding of the protein to mannose, and ELISA assays revealed a partial loss of ability of each GRFT point mutant to bind gp120, with a near-complete loss of binding by the triple mutant D30A/D70A/D112A GRFT. A more quantitative surface plasmon resonance (SPR) examination showed a rather small loss of binding to gp120 for the individual GRFT point mutants ( $K_{\mathrm{D}}$ : 123 to 245 pM range versus 73 pM for wildtype GRFT), but dramatic loss of the triple mutant to bind gp120 derived from R5 and X4 strains $\left(K_{\mathrm{D}}>12 \mathrm{nM}\right)$. In contrast to the 2- to 3-fold loss of binding to gp120, the single CBS point mutants of GRFT were significantly less able to inhibit viral infection, exhibiting a 26- to 1900 -fold loss of potency, while the triple mutant was at least 875 -fold less effective against HIV-1 infection. The disparity between HIV-1 gp120 binding ability and HIV inhibitory potency for these GRFT variants indicates that gp120 binding and virus neutralization do not necessarily correlate, and suggests a mechanism that is not based on simple gp120 binding.
\end{abstract}

KEYWORDS: griffithsin (GRFT), lectin, HIV entry inhibitor, microbicide, carbohydrate binding site (CBS), nuclear magnetic resonance (NMR), mannose titration, analytical ultracentrifugation, surface plasmon resonance (SPR)

\section{INTRODUCTION}

In the fight against HIV/AIDS, HIV entry inhibition is increasingly important. To inhibit entry of the virus, general strategies include the development of drugs that interact with the HIV envelope proteins gp120 and gp41, or that interact with human cell surface proteins that are the targets of the virus, such as the coreceptor CCR5. ${ }^{1-3}$ One important class of potent HIV entry inhibitors is the lectin class, which bind to the glycans that cover the surface of HIV gp120. In particular, the branched mannose oligomers Man- 8 and Man- 9 on HIV-1 gp120 are the likely target of inhibitors such as cyanovirin-N and griffithsin (GRFT), ${ }^{4-9}$ each of which are highly potent HIV inhibitors in cell culture.

GRFT is a lectin derived from a red alga and is among the most efficient anti-HIV lectins, showing low nanomolar inhibition in cell fusion assays and subnanomolar inhibition against single round and replication-competent HIV. ${ }^{3}$ GRFT has been shown to be produced easily in gram quantities, ${ }^{10}$ and to be nonirritating and largely unable to activate cellular receptors under conditions necessary for clinical use. ${ }^{11,12}$ Therefore, this protein is considered as a leading drug candidate to prevent the sexual spread of HIV.

GRFT has been crystallized as a domain-swapped dimer, and several high resolution structures have shown three putative carbohydrate-binding sites (CBS) on each monomer (Figure 1). ${ }^{4-6,13}$ Each site appears to be able to bind only one glycan unit, but affinity studies with monosaccharides show only a micromolar binding potential. Therefore, some combination of glycan binding by the multiple sites on GRFT, rather than by individual sites, seems to be necessary to achieve high levels of virus inhibition. Mechanistic work on the particular sites of

Received: April 9, 2012

Revised: July 10, 2012

Accepted: July 24, 2012

Published: July 24, 2012 

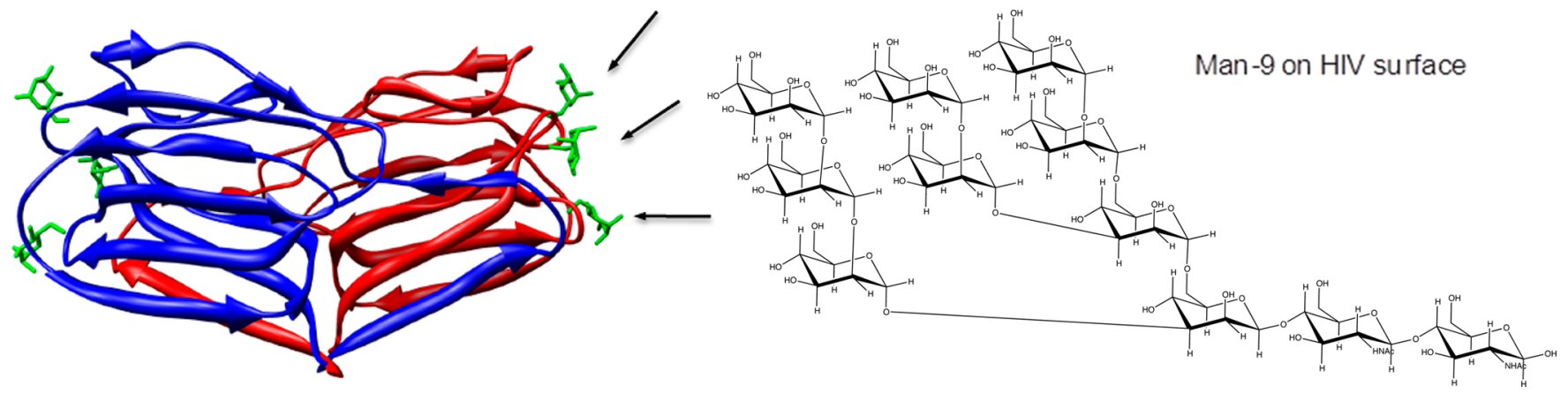

Figure 1. Left: The structure of the GRFT dimer in complex with mannose. ${ }^{5}$ The arrows denote the three mannose binding sites of one monomer. Right: The structure of Man-9, ${ }^{9}$ an oligosaccharide on the surface of gp120 that is likely bound by GRFT. The protein structure was made with the program Chimera ${ }^{34}$ using PDB structure 2 gud.

glycosylation of gp120 reveals the likely importance of N-linked carbohydrates at N295, N234, and N448 in the action of GRFT. ${ }^{14-16}$ Calculations have been carried out suggesting that all three sites on a GRFT subunit could indeed be used simultaneously to bind the three terminal mannose residues of the branched Man-9 of gp $120 .^{6}$ However, more recent structural work by these research groups shows that an engineered GRFT monomer "1GS-S" in complex with nonamannoside does not appear to have all three sites bound simultaneously to the three terminal mannose groups of a highmannose glycan. In this structure, two of the terminal mannoses bind in two sites on GRFT (pocket 1 and pocket 3 , using the nomenclature from Ziolkowska $2006^{4,5}$ ), while the pocket 2 site was bound by a mannose from another symmetry related nona-mannoside. ${ }^{4}$ This work indicated that this pocket 2 site (with key residue Asp30) was not equivalent to the other two sites within the monomeric subunit, and emphasized the role of the GRFT dimer by showing that a monomeric variant was greatly diminished in its ability to inhibit HIV. ${ }^{4}$

Therefore, an outstanding question regarding the mechanism of HIV inhibition by GRFT is the role each of the three putative carbohydrate-binding sites plays in the affinity of the protein for its mannose target and subsequent anti-HIV function. Here, we show the effect on the structure and function of GRFT when each individual CBS is mutated. We also present NMR chemical shift assignments of wild-type GRFT and describe further biochemical investigations of the wild-type protein and its mutants, including analytical ultracentrifugation, surface plasmon resonance and assessment of carbohydrate binding and anti-HIV function of wild-type and mutant GRFT.

\section{EXPERIMENTAL METHODS}

DNA Construction. Single site mutations of GRFT (D30A, D70A, D112A) were made using Stratagene QuikChange SiteDirected Mutagenesis or using a standard thermocycling strategy. Genes of GRFT variants were cloned into the pET$15 \mathrm{~b}$ expression vector (Novagen) between the Ncol and Bam H1 cleavage sites. The triple mutation of GRFT (D30A/ D70A/D112A) was made using a standard thermocycling strategy, and all mutants were confirmed by DNA sequencing.

Protein Production and Purification. Plasmids with an N-terminal histidine-tag were transformed to Escherichia coli BL21(DE3) (Novagen) competent cells and expressed in minimal media with ${ }^{15} \mathrm{NH}_{4} \mathrm{Cl}$ as the sole nitrogen source. Each mutant was produced using the following procedure. Protein production was induced upon addition of isopropyl $\beta$-D-1- thiogalactopyranoside (IPTG) with further incubation at $37^{\circ} \mathrm{C}$ for $6 \mathrm{~h}$. Cells were harvested by centrifugation at $6000 \mathrm{~g}$ for 10 min, and the pellet was resuspended in $5 \mathrm{M}$ guanidine hydrochloride, $500 \mathrm{mM} \mathrm{NaCl}, 10 \mathrm{mM}$ benzamidine, and 20 $\mathrm{mM}$ Tris $\mathrm{pH} 8$; this allowed complete solubilization of proteins from both the inclusion body and the supernatant upon cell disruption. The solution was French pressed twice at 16,000 psi, and then centrifuged at $15000 \mathrm{~g}$ for $1 \mathrm{~h}$. The soluble portion was loaded onto a Ni chelating column (Qiagen) equilibrated with the same resuspension buffer. Proteins that bind nonspecifically were first eluted in the same buffer in the presence of $50 \mathrm{mM}$ imidazole. These were discarded. Finally, GRFT or its variants were then eluted using $500 \mathrm{mM}$ imidazole, $5 \mathrm{M}$ guanidine hydrochloride, $500 \mathrm{mM} \mathrm{NaCl}$ and $20 \mathrm{mM}$ Tris $\mathrm{pH} 8$ and refolded by adding dropwise to low salt refolding buffer $(50 \mathrm{mM} \mathrm{NaCl}, 20 \mathrm{mM}$ Tris $\mathrm{pH} 8)$ over the course of 30 min. The solution was dialyzed against in the same refolding buffer at $4{ }^{\circ} \mathrm{C}$ overnight. The protein solution was then centrifuged at $15000 \mathrm{~g}$ for $1 \mathrm{~h}$ to remove precipitated material, and purified on a $\mathrm{C} 4$ reversed-phase chromatography column (Vydac, Hesperia, CA). The fractions were analyzed on a SDSPAGE gel to confirm the size and then lyophilized in a Labconco freeze-dry system (Labconco Corporation).

For the D30A/D70A/D112A triple mutation, in some preps a slight variation was used. The cell pellet was resuspended in high salt cracking buffer ( $500 \mathrm{mM} \mathrm{NaCl}, 20 \mathrm{mM}$ Tris $\mathrm{pH} 8$ ) without the presence of guanidinium so that only the supernatant was used without further refolding. The purification continued as described above, in buffers lacking guanidinium using a nickel chelating column, followed by dialysis and $\mathrm{C} 4$ column purification.

Concentration of protein was determined using absorbance at $280 \mathrm{nM}$ with an extinction coefficient of GRFT subunit (11920 $\mathrm{cm}^{-1} \mathrm{M}^{-1}$, from the Expasy program located at http:// web.expasy.org/protparam/) except as described for analytical ultracentrifugation, which also used $A_{230}$. Results indicate the concentration of GRFT subunits (monomers), except for the surface plasmon resonance, which show the concentration of dimers, since those were established here to be the relevant binding unit.

GRFT Binding to D-Mannose-agarose Column. The Dmannose-agarose column was obtained from Sigma (St. Louis, $\mathrm{MO}$ ) and is composed of a single mannose saccharide bound to the agarose bead, likely through the C6 hydroxyl. GRFT was made to $15 \mu \mathrm{M}$ in $50 \mathrm{mM}$ Tris $\mathrm{pH} 7.4$ and bound to the column. Elution was carried out with a gradient up to $200 \mathrm{mM}$ mannose, $50 \mathrm{mM}$ Tris $\mathrm{pH}$ 7.4. 
ELISA Studies of GRFT-gp120 Interactions. To test the binding of each GRFT mutant to HIV gp120, ELISA binding assays were carried out as described previously. ${ }^{3,17}$ In brief, 100 ng of HIV gp120 ${ }_{\mathrm{ADA}}$ (ImmunoDiagnostic) was coated on each well in a 96 well plate (Maxisorp Immunoplate; Nalge NUNC) overnight at $4{ }^{\circ} \mathrm{C}$. After the plate was washed with $0.5 \%$ Tween 20 in PBS and blocked with $1 \%$ bovine serum albumin for $1 \mathrm{~h}$, serial dilutions of wild-type GRFT or its mutants were added to triplicate wells and incubated for $2 \mathrm{~h}$ at $37^{\circ} \mathrm{C}$. After the plate was washed, a 1:1000-fold dilution of horseradishperoxidase-conjugated nickel-NTA (Qiagen) (which detects the N-terminal his-tag of GRFT and its mutants) was added according to the company's instructions. Then the substrate for horseradish-peroxidase (2,2'-azino-bis 3-ethylbenzthiazoline-6sulfonic acid; ABTS) (Fisher Scientific) was added and signal was measured by absorbance at $405 \mathrm{~nm}$.

Virus Isolates. HIV virions deleted in vpr and env were used to make pseudo viral particles as follows. Viral plasmids containing the env gene from HIV-1 were obtained from the NIH AIDS Research and Reference Reagent Program, Division of AIDS, NIAID, NIH, as follows: HIV-1 ADA-M (referred to as HIV-1 ADA, R5) was from Dr. Howard Gendelman. ${ }^{18-21}$ Plasmid pSV-JRFL (R5) was a kind gift from Nathaniel Landau. ${ }^{22}$ pCAGGS-SF162-gp160 (R5) was from Leonidas Stamatatos and Dr. Cecilia Cheng-Mayer. ${ }^{23-25}$ 293FT cells were kind gifts from Dr. Jennifer Manilay and were originally obtained from Invitrogen. For single round virus production, plasmids with deleted vpr and env ( $\mathrm{pNL}-\mathrm{luc} 3-\mathrm{R}^{-} \mathrm{E}^{-}$containing the firefly luciferase gene; a kind gift from Dr. Nathaniel Landau ${ }^{22}$ ) were cotransfected into 293FT cells with different HIV strain env plasmids using Roche X-treme HP transfection reagent according to the manufacturer's instructions. Supernatant medium containing virions was harvested $48 \mathrm{~h}$ post transfection, centrifuged at $1000 \mathrm{~g}$, filtered through a $0.45 \mu \mathrm{M}$ syringe (Millipore) and stored at $-80{ }^{\circ} \mathrm{C}$ for later experiments. HIV-1 $\left(\mathrm{III}_{\mathrm{B}}\right)$ was provided by R. C. Gallo, at that time at the National Institutes of Health (Bethesda, MD).

Single-Round Infection Assays. TZM-bl cells stably expressing CD4, CCR5 and CXCR4 coreceptors were maintained in Dulbecco's modified Eagle's medium (DMEM) with $10 \%$ fetal bovine serum (FBS). $10^{4}$ cells per well were first seeded into a 96-well plate for one day. The medium was then changed $3 \mathrm{~h}$ before the assay and made to a volume of $50 \mu \mathrm{L}$ per well, and then a serial dilution of GRFT variants was added from the top row to the bottom row, as follows: $20 \mu \mathrm{L}$ of GRFT variants of different concentration was added into the first row and mixed well with culture medium. Then $20 \mu \mathrm{L}$ of medium was removed and added into the second row, and so on. Virus was then added into each well containing different GRFT variants. The medium was changed in $24 \mathrm{~h}$, and cells were incubated for another $24 \mathrm{~h}$. PBS containing $0.5 \%$ NP-40 was used to lyse the cells, and substrate chlorophenol red-Dgalactopyranoside [CPRG] (Calbiochem) was added. Signal was measured at $570 \mathrm{~nm}$ and $630 \mathrm{~nm}$ (absorbance). The ratio of 570/630 for each well was calculated. $\mathrm{EC}_{50}$ values were determined using a linear equation fitted between two data points surrounding 50\% inhibition. For presentation purposes, data shown in the figures were plotted and fitted as curves using a four-parameter logistic equation in Kaleidagraph (Synergy Software, Reading, PA).

Anti-HIV Assays in CEM Cell Cultures. CEM cells $(5 \times$ $10^{5}$ cells per $\mathrm{mL}$ ) were suspended in fresh culture medium and infected with $\mathrm{HIV}-1\left(\mathrm{III}_{\mathrm{B}}\right)$ at 100 times the $\mathrm{CCID}_{50}(50 \%$ cell culture infective dose) per $\mathrm{mL}$ of cell suspension, of which 100 $\mu \mathrm{L}$ was then mixed with $100 \mu \mathrm{L}$ of the appropriate dilutions of the test compounds. After 4 to 5 days at $37{ }^{\circ} \mathrm{C}$, HIV-1-induced syncytia formation was recorded microscopically in the cell cultures. The $50 \%$ effective concentration $\left(\mathrm{EC}_{50}\right)$ corresponds to the compound concentration required to prevent syncytium formation by $50 \%$ in the virus-infected CEM cell cultures.

Cocultivation Assay. Persistently HIV-1 $\left(\mathrm{III}_{\mathrm{B}}\right)$-infected HuT-78 cells were washed to remove free virus from the culture medium, and $5 \times 10^{4}$ cells $(50 \mu \mathrm{L})$ were transferred to 96-well microtiter plates. Next, a similar amount of Sup-T1 cells $(50 \mu \mathrm{L})$ and appropriate concentrations of test compound (100 $\mu \mathrm{L}$ ) were added to each well. After 2 days of coculturing at 37 ${ }^{\circ} \mathrm{C}$, the $\mathrm{EC}_{50} \mathrm{~s}$ were quantified by microscopic inspection on the basis of the appearance of syncytia.

NMR Spectroscopy. GRFT variants were expressed in minimal media with ${ }^{15} \mathrm{NH}_{4} \mathrm{Cl}$ as the only nitrogen source or with ${ }^{15} \mathrm{NH}_{4} \mathrm{Cl}$ as well as ${ }^{13} \mathrm{C}$ labeled glucose as the sole nitrogen and carbon source. These mutants were produced and purified as described above. To dissolve the protein powder after purification, $20 \mathrm{mM}$ sodium phosphate buffer ( $\mathrm{pH} 7.0)$ with 5\% $\mathrm{D}_{2} \mathrm{O}$ was used and 2,2-dimethyl-2-silapentane-5-sulfonic acid (DSS) was added for calibration. Spectra were collected at 25 ${ }^{\circ} \mathrm{C}$ on a four-channel $600 \mathrm{MHz}$ Bruker Avance III spectrometer. The backbone resonances were assigned using standard spectra: 3D HNCO, $\mathrm{HN}(\mathrm{CA}) \mathrm{CO}, \mathrm{HNCACB}$, $\mathrm{CBCA}(\mathrm{CO}) \mathrm{NH}, \mathrm{HNCA}, \mathrm{HN}(\mathrm{CO}) \mathrm{CA}^{26-29}$ Data was processed using NMRPipe. ${ }^{30}$ The programs PIPP, Sparky and NMRVIEW $^{31-33}$ were used for visualization and chemical shift assignment. Molecular graphics images were produced using the UCSF Chimera package from the Resource for Biocomputing, Visualization, and Informatics at the University of California, San Francisco (supported by NIH P41RR001081). ${ }^{34}$ Changes in backbone chemical shift $\left(\Delta \delta_{\text {obs }}\right)$ upon mutation or titration with mannose were determined using the weighted average of changes in ${ }^{1} \mathrm{H}$ and ${ }^{15} \mathrm{~N}$, with the equation ${ }^{35-37}$

$$
\Delta \delta_{\text {obs }}=\left\{\left[\Delta \delta_{\mathrm{HN}}^{2}+\left(\Delta \delta_{\mathrm{N}} / 5\right)^{2}\right] / 2\right\}^{1 / 2}
$$

Surface Plasmon Resonance (SPR) Analysis. Recombinant gp120 proteins from $\mathrm{HIV}-1\left(\mathrm{III}_{\mathrm{B}}\right)$ strain (ImmunoDiagnostics Inc., Woburn, MA), from HIV-1(ADA) strain (ImmunoDiagnostics) and recombinant gp41 protein from HIV-1(HxB2) (Acris Antibodies GmbH, Herford, Germany) were covalently immobilized on the carboxymethylated dextran matrix of a CM5 sensor chip in $10 \mathrm{mM}$ sodium acetate, $\mathrm{pH} 4.0$, using standard amine coupling chemistry. The exact chip densities are given in the Results. A reference flow cell was used as a control for nonspecific binding and refractive index changes. All interaction studies were performed at $25^{\circ} \mathrm{C}$ on a Biacore T200 instrument (GE Healthcare, Uppsala, Sweden). The test compounds were serially diluted in HBS-P (10 mM HEPES, $150 \mathrm{mM} \mathrm{NaCl}$ and $0.05 \%$ surfactant P20; $\mathrm{pH} 7.4$ ) covering a concentration range between 1.51 and $12.05 \mathrm{nM}$ by using 2-fold dilution steps. Samples were injected for $2 \mathrm{~min}$ at a flow rate of $45 \mu \mathrm{L} / \mathrm{min}$ and the dissociation was followed for 8 min. One duplicate sample and several buffer blanks were used as a positive control and for double referencing, respectively. The CM5 sensor chip surface was regenerated with 1 injection of glycine- $\mathrm{HCl} \mathrm{pH} \mathrm{1.5.} \mathrm{The} \mathrm{experimental} \mathrm{data} \mathrm{were} \mathrm{fit} \mathrm{using} \mathrm{the}$ 1:1 binding model (Biacore T200 Evaluation software 1.0) to determine the binding kinetics. In a separate experiment, both monomeric gp120 and trimeric gp140 derived from HIV-1/JR- 
FL (kind gift from R. W. Sanders, Amsterdam, The Netherlands) ${ }^{38}$ were bound on the CM5 sensor chip and interaction of wild-type GRFT was site-by-site investigated against both monomers and trimers as described above. Also recombinant nonglycosylated gp 160 (derived from $\mathrm{HIV}-1 / \mathrm{III}_{\mathrm{B}}$ and expressed in E. coli (ImmunoDiagnostics Inc., Woburn, MA)) was covalently immobilized on the CM5 sensor chip as described above, and its interaction with wild-type and mutant GRFT, but also the carbohydrate-binding monoclonal antibody 2G12 (Polymun Scientific GmbH, Vienna, Austria), soluble $\mathrm{CD}_{4}\left(\mathrm{sCD}_{4}\right)$ (ImmunoDiagnostics Inc.), and the $\alpha 1,3 / \alpha 1,6-$ mannose-specific plant lectin from Hippeastrum hybrid (HHA) (provided by E. Van Damme, Ghent, Belgium), was investigated.

Analytical Ultracentrifugation. Sedimentation velocity experiments were carried out to confirm that the mutations did not affect the dimeric oligomerization state of GRFT. All experiments were performed on a Beckman Optima XL-I at the Center for Analytical Ultracentrifugation of Macromolecular Assemblies (CAUMA) at the University of Texas Health Science Center at San Antonio. Sedimentation velocity (SV) data were analyzed with the UltraScan software. ${ }^{39,40}$ Calculations were performed at the Texas Advanced Computing Center at the University of Texas at Austin, and at the Bioinformatics Core Facility at the University of Texas Health Science Center at San Antonio as described in ref 41. All GRFT samples were measured in $40 \mathrm{mM}$ sodium phosphate buffer ( $\mathrm{pH}$ 6.9), except for the triple mutant D30A/D70A/D112A which also included $50 \mathrm{mM} \mathrm{NaCl}$. To monitor possible mass action in the oligomerization behavior of GRFT, the data were measured in intensity mode both at 0.3 and $0.9 \mathrm{OD}$ at 230 and $280 \mathrm{~nm}(0.3,0.6,0.9$ at $230 \mathrm{~nm}$ for the triple mutant D30A/ $\mathrm{D} 70 \mathrm{~A} / \mathrm{D} 112 \mathrm{~A})$, giving access to a wide concentration range. All data were collected at $20{ }^{\circ} \mathrm{C}$, and spun at $50 \mathrm{krpm}$, using standard titanium 2-channel centerpieces (Nanolytics, Potsdam, Germany). The protein concentrations ranged from 4.2 $\mu \mathrm{M}\left(0.3 \mathrm{OD}_{230 \mathrm{~nm}}\right)$ to $75.5 \mu \mathrm{M}\left(0.9 \mathrm{OD}_{280 \mathrm{~nm}}\right)$. The partial specific volume of GRFT was determined to be $0.7128 \mathrm{~cm}^{3} / \mathrm{g}$ for wild-type GRFT and $0.7138 \mathrm{~cm}^{3} / \mathrm{g}$ for the D-A mutants by protein sequence according to the method by Durchschlag as implemented in UltraScan. All data were first analyzed by twodimensional spectrum analysis with simultaneous removal of time-invariant noise ${ }^{42,43}$ and then by enhanced van HoldeWeischet analysis ${ }^{44}$ and genetic algorithm refinement ${ }^{45,46}$ followed by Monte Carlo analysis. ${ }^{47}$

\section{RESULTS}

NMR Chemical Shift Assignments of Wild-Type GRFT. Although several high quality X-ray structures of GRFT have been published, ${ }^{4-6,13}$ limited nuclear magnetic resonance (NMR) data has yet been reported. ${ }^{48}$ This technique is quite complementary to X-ray analysis, allowing a quick assessment of whether a protein is folded and the likely structural similarity of a mutant to the wild-type protein. Therefore, the backbone chemical shift determination of wild-type GRFT was carried out using standard methods. We were able to obtain $90.7 \%$ assignments, including backbone ${ }^{15} \mathrm{~N},{ }^{1} \mathrm{H}^{\mathrm{N}},{ }^{13} \mathrm{CO},{ }^{13} \mathrm{C} \alpha$ and $40 \%{ }^{13} \mathrm{C} \beta$; Figure 2 shows an assigned ${ }^{15} \mathrm{~N},{ }^{1} \mathrm{H}$ HSQC (heteronuclear single quantum coherence) correlation spectrum for GRFT.

NMR of GRFT with Mannose. A titration was carried out with wild-type GRFT in the presence of mannose. The addition of the monosaccharide caused a significant shift in several

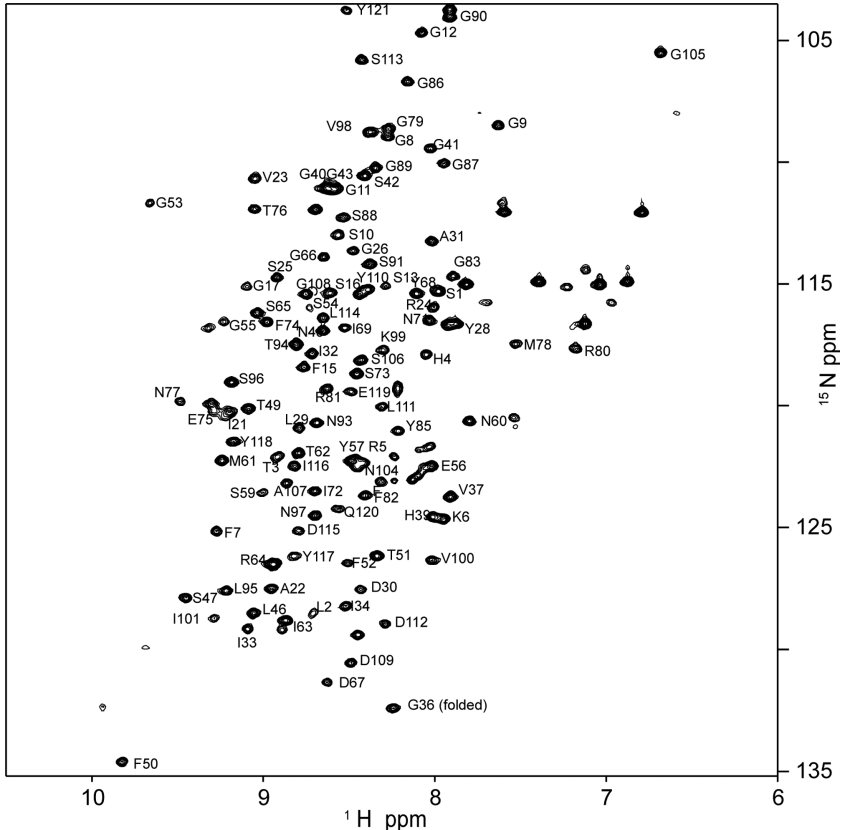

Figure 2. Assigned ${ }^{15} \mathrm{~N}$ correlation spectrum of wild-type GRFT.

peaks, as shown in Figure 3A, indicating a changed environment for these amino acids upon mannose binding. The shifted peaks were identified, and as shown in Figure $3 \mathrm{~B}$ the region most affected by the addition of mannose is the face of the protein containing the three CBS. It was found that 15 residues on this face shifted by at least 1 standard deviation from the average ( 9 shifted by 1 SD, 6 shifted by 2 SD) while only a small amount of shifting occurred elsewhere in the protein (Figure 3B, Figure S1 in the Supporting Information). Also, some of the peaks corresponding to residues on the mannose binding face were impossible to follow upon titration with mannose due to broadening, suggesting a change in dynamics indicative of a binding event.

Mutations of Carbohydrate-Binding Sites in GRFT. As shown in Figure 4A, each mannose moiety interacts with GRFT through several H-bonds. ${ }^{5}$ One of the most clear and defined interactions in each carbohydrate-binding site involves the side chain of Asp 30 (and Asp 70 and Asp 112 in the other nearly identical CBS) and the hydroxyl of $\mathrm{O} 4$ and $\mathrm{O} 6$ in mannose. It appears very likely that if the Asp were removed by mutation to Ala, the sugar binding capability would be severely impaired, likely without harming the overall structure of the protein. However, it cannot be excluded that individual amino acid side chains also contribute to maintain the protein configuration, and therefore, a dramatic amino acid change from Asp to Ala may also affect the conformational structure of the protein. To clarify the role of each putative mannose binding site in GRFT, we mutated the key Asp residue at each CBS to Ala. We also made a triple mutant at all three CBS of GRFT. Each variant was first assessed by NMR and shown to be folded (Figure 4B and Figure S2 in the Supporting Information). A comparison of HSQC spectra with the wild-type protein indicates that each point mutant has changes that extend further than its individual site, propagating to much of the mannose-binding face of the protein, including usually each of the other two sites, while the remainder of the protein appears to be largely unaffected (Figures 4C, 4D and Figure S2 in the Supporting Information). The largest changes in spectra were observed for the triple 

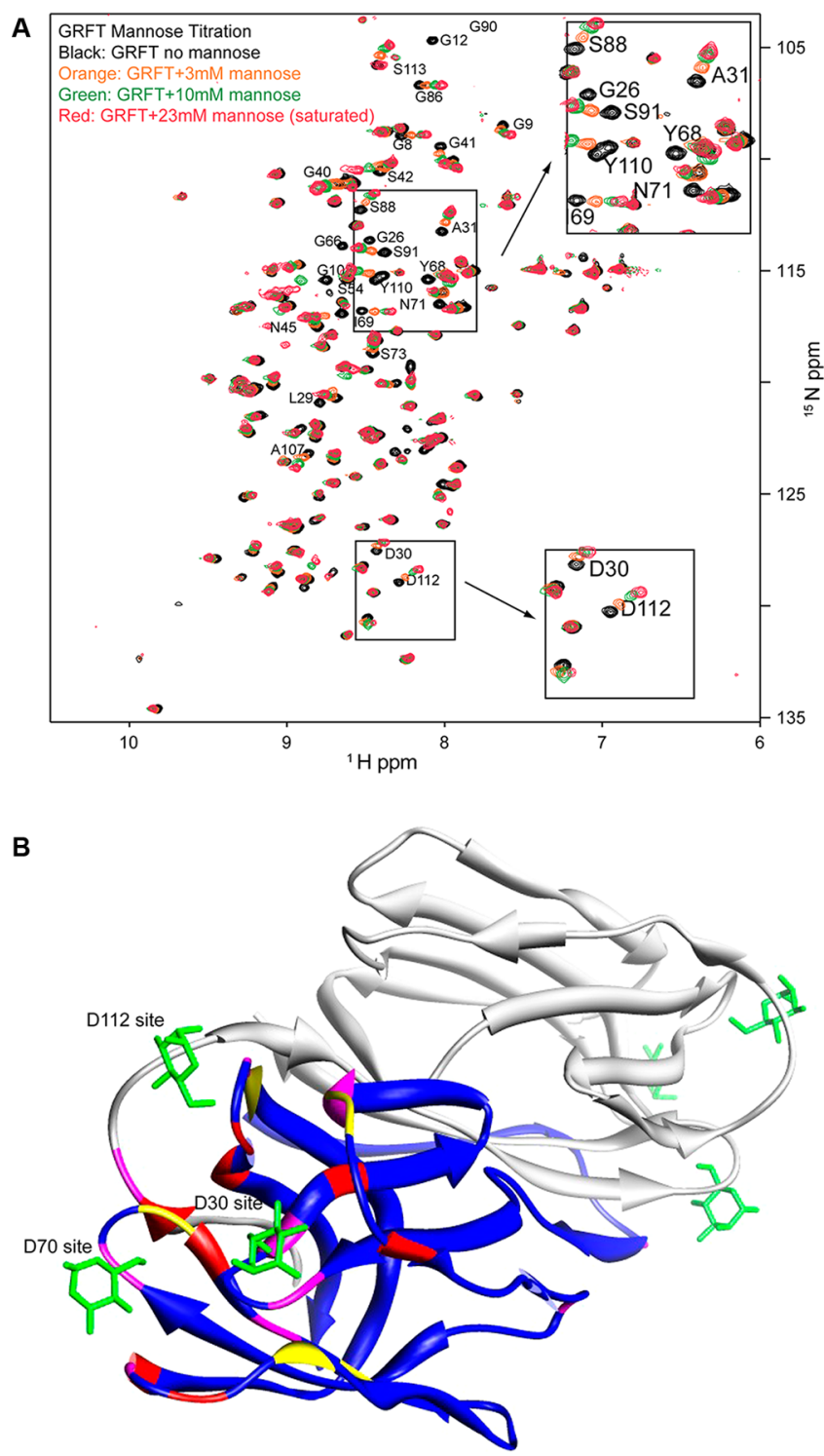

Figure 3. (A) ${ }^{15} \mathrm{~N}$ HSQC of mannose titration of GRFT. Resonances for unliganded wild-type protein are shown in black. Orange peaks represent GRFT in the presence of $3 \mathrm{mM}$ mannose; green peaks show the presence of $10 \mathrm{mM}$ mannose; red peaks show the presence of 23 $\mathrm{mM}$ mannose (saturated). (B) Structure of GRFT showing regions from one subunit of the protein affected by titration with mannose, as determined by NMR spectroscopy. Yellow indicates residues whose chemical shift changed by 1 standard deviation from the average upon addition of mannose, while red indicates residues whose chemical shift changed by 2 standard deviations, and magenta indicates residues that became impossible to follow upon addition of mannose. These residues are listed in Table $\mathrm{S} 1$ in the Supporting Information. Mannose monosaccharides are shown in green. Residues G8 and G9 are from the domain-swapped other subunit. Structure is PDB 2gud obtained from ref 5 .

mutant, having the Asp at each of the three CBS mutated to Ala (Figure S3 in the Supporting Information). When this triple mutant D30A/D70A/D112A was titrated with mannose, the HSQC spectra showed essentially no change for any concentration tested, up to $23 \mathrm{mM}$ mannose, indicating no binding (Figure S6 in the Supporting Information).

To determine whether the mutations at each CBS in GRFT altered the dimer affinity, analytical ultracentrifugation was carried out on the wild-type protein and each variant using sedimentation velocity analysis. To better ascertain whether any mass action effects were detectable, wild-type and mutant GRFT were measured over a wide concentration range. In each case vertical sedimentation coefficient $G(s)$ distributions were obtained with the enhanced van Holde-Weischet analysis, ${ }^{44}$ and had nearly identical sedimentation coefficients (see Figure 5 and Figure S4 in the Supporting Information). Vertical G(s) distributions indicate that all samples were homogeneous. ${ }^{49} 2$ Dimensional spectrum analysis ${ }^{42,43}$ combined with Monte Carlo analysis ${ }^{47}$ resulted in a molecular weight consistent only with the dimer (see Table 1), even at the lowest concentration tested $(4.2 \mu \mathrm{M})$.

Mutations in the CBS of GRFT Reduce the Ability of GRFT To Bind Mannose and gp120. The ability of wild-type GRFT and its variants to bind mannose was first assessed by using a commercial mannose column, having mannose monosaccharide bound to a standard bead. This column is a crude method of determining mannose binding, since the attachment of each carbohydrate to the bead at C6 precludes protein binding from that direction. Each protein was loaded onto the column and eluted using a mannose gradient. GRFT bound to the column, requiring $50 \mathrm{mM}$ mannose for elution, while mutation at any single CBS resulted in a protein that flowed through without binding the column (data not shown). This indicates that carbohydrate binding was diminished for each mutant, but since the column is composed of a single carbohydrate ring that is not freely available at all sites for binding, further interpretation is not possible.

The most relevant binding interaction for GRFT in terms of HIV inhibition is its ability to bind HIV envelope protein gp 120. A straightforward way to measure this interaction is the ELISA assay, in which gp120 is bound to a surface, and varying amounts of GRFT or its mutants are exposed to the gp120. The level of binding between GRFT and gp120 is determined by addition of a peroxidase-conjugated protein that is specific for the N-terminal His-tag on GRFT. (We and others have shown that an N-terminal His-tag does not impede the activity of GRFT $^{3,48}$ ). As shown in Figure 6A, wild-type GRFT binds very well to gp120 derived from HIV-1 strain ADA, with clear binding between $10 \mathrm{nM}$ and $100 \mathrm{nM}$. In contrast, each point mutant binds gp120 less well, requiring $100 \mathrm{nM}$ to $1,000 \mathrm{nM}$. In general, the GRFT point mutant D70A, having a mutation at the so-called pocket $3,{ }^{4}$ repeatedly appeared to bind the worst in these experiments under the same conditions, although ELISA experiments are not quantitative. The triple GRFT mutant D30A/D70A/D112A binds very poorly to gp120, showing only a low signal increase at the high-tested amount of $1.28 \mu \mathrm{M}$. Therefore, overall the single point mutants show an approximate 10 -fold reduced ability to bind, while the triple mutant binds much more weakly to gp120.

A more quantitative way to determine binding to the HIV-1 envelope is the use of surface plasmon resonance (SPR). ${ }^{50,51}$ In this experiment, binding properties of GRFT and its mutants were evaluated against monomeric gp120 $\mathrm{III}_{\mathrm{B}}$ (X4) and gp120 ADA (R5), and also against the glycosylated HIV-1 (HxB2) gp41 fusion protein. All ligands were covalently immobilized on CM5 sensor chips, and $140 \mathrm{RU}(\sim 1.17 \mathrm{fmol}), 90 \mathrm{RU}(\sim 0.75$ fmol) and $240 \mathrm{RU}(\sim 5.85 \mathrm{fmol})$ of gp120 density were obtained, respectively. Such low gp120 density chips are required to enable reliable determination of $K_{\mathrm{D}}$ values, since high gp120-density chips may easily allow rebinding of GRFT to another gp120 molecule on the same sensor chip resulting in erroneous $k_{\text {off }}$ rate determinations. The binding and release of 

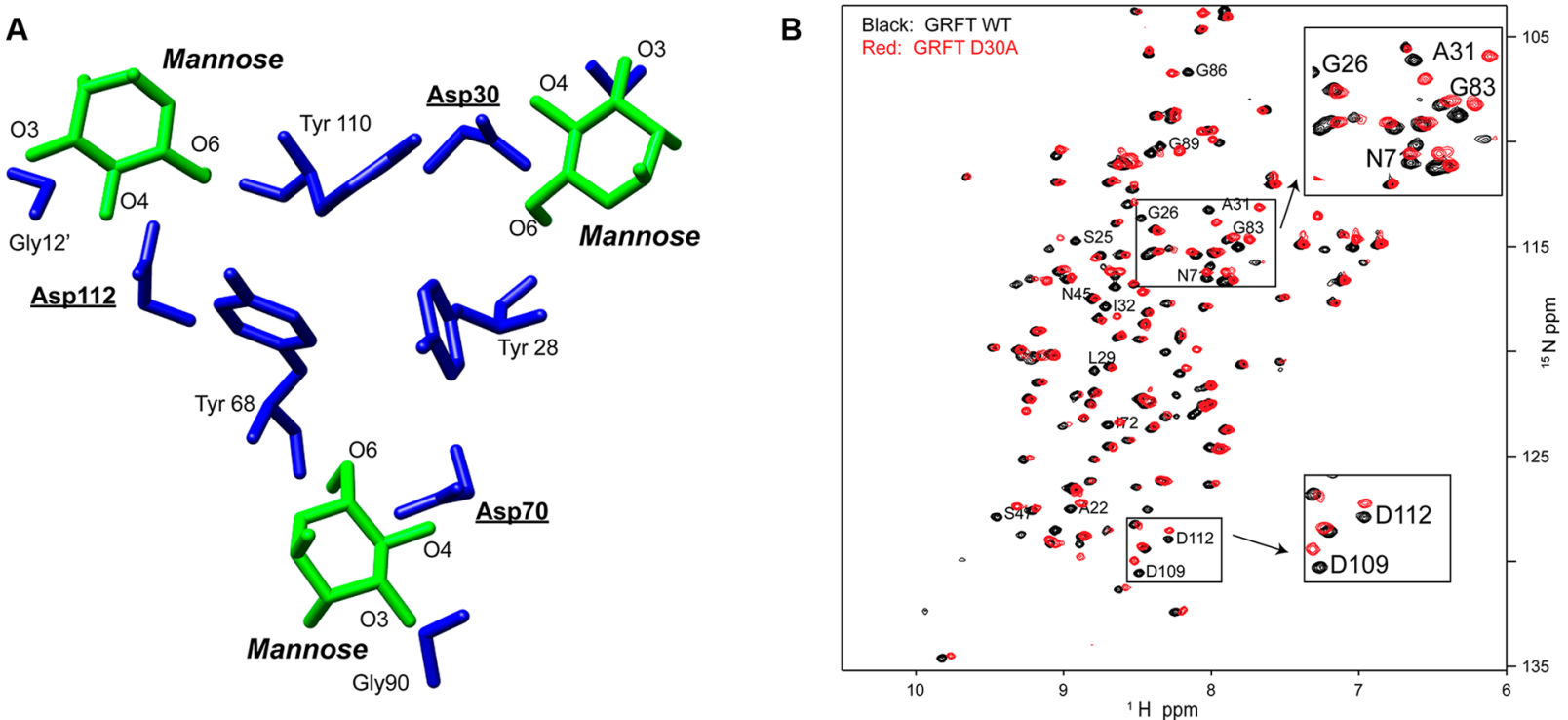

C
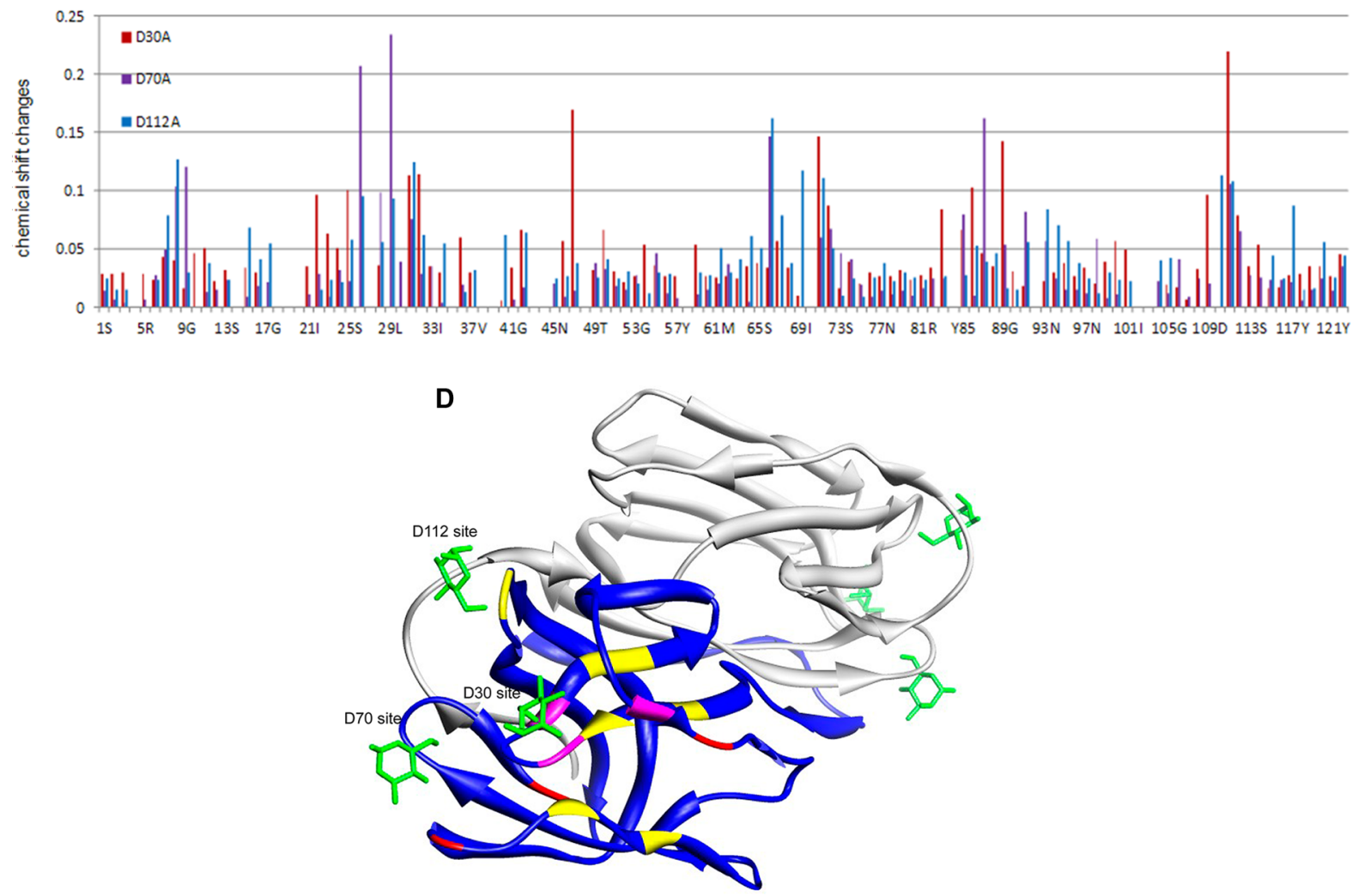

Figure 4. (A) The three putative mannose binding sites of GRFT, as determined by ref 5. Mannose saccharide is shown in green; selected residues from griffithsin are shown in blue and labeled. (B) ${ }^{15} \mathrm{~N}$ HSQC spectrum of GRFT D30A (red) overlaid with the spectrum of wild-type griffithsin. Some peaks with significant movement upon mutation are labeled. (C) Chemical shift changes of GRFT upon mutation of residues at the mannose binding sites. Some residues broaden or move and cannot be visualized upon mutation of one of the sites so they are not shown. Changes for D30A are shown in red; D70A, purple; D112A, blue. (D) Structure of GRFT showing regions that have chemical shift changes upon mutation of the mannose site at D30. Yellow indicates chemical shift change that is 1 standard deviation greater than average, red indicates chemical shift change that is 2 standard deviations greater than average, and magenta indicates peaks that broaden or otherwise have moved too much to assign upon mutation. These residues are listed in Table S1 in the Supporting Information. Mannose residues are shown in green. Structure is 2 gud from ref 5.

GRFT (concentration expressed in dimer units) can be measured in real time to provide on- and off-rates as well as affinity constants $\left(K_{\mathrm{D}}\right.$ values $)$. As shown in Figure $6 \mathrm{~B}$ and Table 2, wild-type GRFT binds very tightly to gp 120 derived from the $\mathrm{X} 4$ strain $\mathrm{III}_{\mathrm{B}}$ as well as the $\mathrm{R} 5$ strain $\mathrm{ADA}$, with $K_{\mathrm{D}}$ values of $72.7 \pm 1.7 \mathrm{pM}$ and $73.2 \pm 2.0 \mathrm{pM}$, respectively. The basis for the tight binding appears to be a fast on-rate $\left(k_{\text {on }}\right)$ (about $6.3 \times$ $\left.10^{6} \mathrm{M}^{-1} \mathrm{~s}^{-1}\right)$ and a slow off-rate $\left(k_{\text {off }}\right)$ (about $\left.5 \times 10^{-4} \mathrm{~s}^{-1}\right)$. The binding kinetics for gp120 derived from $\mathrm{HIV}-1\left(\mathrm{III}_{\mathrm{B}}\right)$ and HIV-1(ADA) were very similar regarding the $K_{\mathrm{D}}$ as well as the $k_{\text {on }}$ and $k_{\text {off }}$ rates (Table 2 and Figure S5A-C in the Supporting Information). Since the native form of gp120 is a trimer in the 


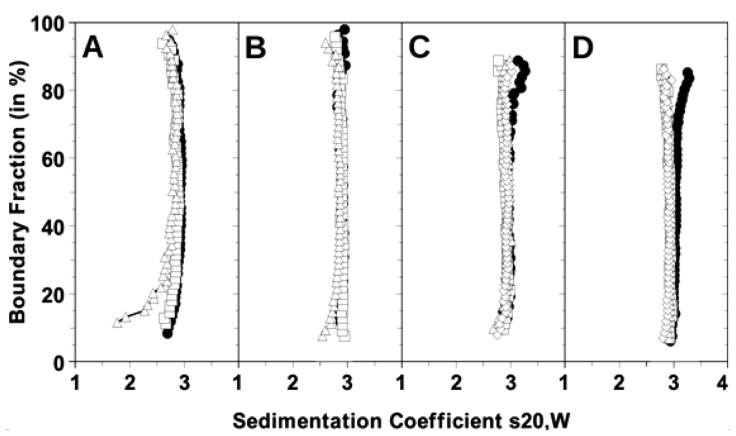

Figure 5. Van Holde-Weischet $G(s)$ sedimentation coefficient distributions of GRFT at 4 concentrations: (A) $0.3 \mathrm{OD} 230 \mathrm{~nm}$; (B) 0.9 OD $230 \mathrm{~nm}$; (C) 0.3 OD $280 \mathrm{~nm}$; (D) 0.9 OD $280 \mathrm{~nm}$. Filled circles: wild-type. Open squares: D30A. Open triangles: D112A. Open diamonds: D70A. Vertical distributions indicate homogeneity.

viral envelope, the binding of GRFT to trimeric gp140 has also been evaluated side by side, but no significant difference in the $K_{\mathrm{D}}$ value was observed $\left(K_{\mathrm{D}}: 0.111 \mathrm{nM}\right.$ and $0.152 \mathrm{nM}$, respectively). GRFT also binds well to gp41 with a similar affinity constant compared to gp120, although this viral fusion protein is only exposed at a later stage of the entry process ${ }^{52,53}$ and most likely does not play a relevant role in the eventual anti-HIV activity of GRFT.

While each point mutant of GRFT showed reduced binding to gp120 derived from both X4 and R5 HIV-1 strains, the effect was small, with D30A and D112A generally exhibiting an as little as 2 -fold reduction in binding compared to the wild-type protein, while the point mutant D70A showed only a 3-fold reduction in affinity. The triple mutant D30A/D70A/D112A did not show a binding signal when exposed to gp120 at $12 \mathrm{nM}$ (Table 2). However, higher concentrations (i.e., 24 and $48 \mathrm{nM}$ ) start to show an interaction signal for binding to gp120 and gp41 (Figure S5D in the Supporting Information).

In an attempt to reveal the binding capacity of wild-type GRFT and its mutants to specific sites of gp120 other than the N-glycans, E. coli-expressed nonglycosylated gp160 was bound to the sensor chip, and binding of the GRFTs but also the carbohydrate-recognizing mAb 2G12, the $\alpha 1,3 / \alpha 1,6$-mannoserecognizing plant lectin $\mathrm{HHA}$ and $\mathrm{sCD}_{4}$ was examined in comparison with their binding to the glycosylated gp120. Whereas binding of GRFT, mutant GRFT, 2G12, HHA and $\mathrm{sCD}_{4}$ to glycosylated gp120 was observed, no significant binding for GRFT, mutant GRFT, 2G12 and HHA was found for nonglycosylated gp160 (Figure $6 \mathrm{C}$ ). Instead, $\mathrm{sCD}_{4}$ that binds to gp120 without the requirement of the presence of $\mathrm{N}$ glycans could still bind to nonglycosylated gp160 (Figure 6C, middle panel). These data indicate that the interactions of GRFT (and also 2G12 and HHA) are predominantly N-glycandependent.

Mutation of the Individual CBS Markedly Reduces the Anti-HIV Activity of GRFT. GRFT and its variants were tested against several strains of HIV using single-round viral assays. As shown in Table 3 and Figure 6D, while wild-type GRFT inhibited HIV strain $\mathrm{ADA}$ with an $\mathrm{EC}_{50}$ of $10.5 \mathrm{pM}$, the $\mathrm{D} 30 \mathrm{~A}$ mutant and D112A mutant were about 1,000-fold less potent (20.3 and $6.57 \mathrm{nM}$, respectively). The D70A mutant was somewhat a better inhibitor than the other point mutants, with an $\mathrm{EC}_{50}$ of $2.63 \mathrm{nM}$. This is in contrast to the ELISA and SPR results, which showed only a very moderate effect of the mutations for the ability of these GRFT variants to bind gp 120 derived from the HIV-1 strain ADA. However, since this set of gp120 binding and antiviral data only includes the ADA strain, it is premature to assume that the superior antiviral activity of the D70A mutant versus the other mutants is a general phenomenon.

Similar functional results were obtained using R5 HIV-1 strain JR-FL, where wild-type GRFT inhibited single round virus infection with an $\mathrm{EC}_{50}$ of $72.5 \mathrm{pM}$. The D30A and D112A variants were approximately 300 -fold lower in anti-HIV potency than wild-type GRFT, and the D70A mutant exhibited about a 10 -fold greater antiviral potency than the other two point mutants. Again for R5 HIV-1 strain SF162, both D30A and $\mathrm{D} 112 \mathrm{~A}$ variants were reduced in potency compared to the wildtype protein by several hundred fold, while the D70A mutant was worse than the wild-type protein, but better than the other point mutants. When viral inhibition assays using X4 HIV-1 strain $\mathrm{III}_{B}$ in $\mathrm{CEM}$ cell cultures were performed in which inhibition of virus-induced cytopathicity was recorded at day 4 post infection and post addition of the compounds, wild-type GRFT inhibited the virus-induced cytopathicity at an $\mathrm{EC}_{50}$ of $0.109 \mathrm{nM}$, while the point mutants were much worse, ranging from 4.8 to $6.8 \mathrm{nM}$ (Table 3). In this case the D70A variant had quite similar antiviral activity as the other point mutants. In all cases, the triple mutant D30A/D70A/D112A was a very poor antiviral inhibitor, with an $\mathrm{EC}_{50}$ of $95.3 \mathrm{nM}$ for the $\mathrm{III}_{\mathrm{B}}$ strain, and $\mathrm{EC}_{50}$ values being higher than the maximum concentration

Table 1. Molecular Weight of the Major Species Determined with the 2-Dimensional Spectrum Analysis ${ }^{42}$ Combined with Monte Carlo Analysis ${ }^{4}$ for Wild-Type GRFT and Mutant at Four Different Loading Concentrations ${ }^{a}$

\begin{tabular}{|c|c|c|c|c|}
\hline \multirow[b]{2}{*}{ sample/concn } & \multicolumn{2}{|c|}{$230 \mathrm{~nm}$} & \multicolumn{2}{|c|}{$280 \mathrm{~nm}$} \\
\hline & $0.3 \mathrm{OD}$ & $0.9 \mathrm{OD}$ & $0.3 \mathrm{OD}$ & $0.9 \mathrm{OD}$ \\
\hline wild type & $\begin{array}{l}2.71 \times 10^{4}\left(1.584 \times 10^{4},\right. \\
\left.3.83 \times 10^{4}\right)\end{array}$ & $\begin{array}{l}2.73 \times 10^{4}\left(2.39 \times 10^{4},\right. \\
\left.3.27 \times 10^{4}\right)\end{array}$ & $\begin{array}{l}2.83 \times 10^{4}\left(2.15 \times 10^{4},\right. \\
\left.3.11 \times 10^{4}\right)\end{array}$ & $\begin{array}{l}2.98 \times 10^{4}\left(2.70 \times 10^{4}\right. \\
\left.3.10 \times 10^{4}\right)\end{array}$ \\
\hline D30A & $\begin{array}{l}3.15 \times 10^{4}\left(3.03 \times 10^{4}\right. \\
\left.3.20 \times 10^{4}\right)\end{array}$ & $\begin{array}{l}3.04 \times 10^{4}\left(2.81 \times 10^{4},\right. \\
\left.3.28 \times 10^{4}\right)\end{array}$ & $\begin{array}{l}3.15 \times 10^{4}\left(2.35 \times 10^{4},\right. \\
\left.\quad 3.54 \times 10^{4}\right)\end{array}$ & $\begin{array}{l}3.00 \times 10^{4}\left(2.73 \times 10^{4}\right. \\
\left.3.22 \times 10^{4}\right)\end{array}$ \\
\hline D112A & $\begin{array}{l}3.00 \times 10^{4}\left(2.88 \times 10^{4}\right. \\
\left.3.04 \times 10^{4}\right)\end{array}$ & $\begin{array}{l}2.79 \times 10^{4}\left(2.57 \times 10^{4},\right. \\
\left.3.01 \times 10^{4}\right)\end{array}$ & $\begin{array}{l}3.07 \times 10^{4}\left(2.91 \times 10^{4},\right. \\
\left.3.23 \times 10^{4}\right)\end{array}$ & $\begin{array}{l}3.13 \times 10^{4}\left(2.13 \times 10^{4}\right. \\
\left.4.11 \times 10^{4}\right)\end{array}$ \\
\hline D70A & not measd & not measd & $\begin{array}{l}3.01 \times 10^{4}\left(2.81 \times 10^{4},\right. \\
\left.3.13 \times 10^{4}\right)\end{array}$ & $\begin{array}{l}3.01 \times 10^{4}\left(2.89 \times 10^{4}\right. \\
\left.3.27 \times 10^{4}\right)\end{array}$ \\
\hline $\begin{array}{l}\text { GRFT D30A/D70A/ } \\
\text { D112A }\end{array}$ & not measd ${ }^{b}$ & $\begin{array}{l}2.84 \times 10^{4}\left(2.72 \times 10^{4},\right. \\
\left.2.97 \times 10^{4}\right)\end{array}$ & not measd ${ }^{b}$ & not measd ${ }^{b}$ \\
\hline
\end{tabular}

${ }^{a}$ Values in parentheses refer to the $95 \%$ confidence intervals for each fit. In all cases the molecular weight closely matches the molecular weight of the GRFT dimer. ${ }^{b}$ For the triple mutant GRFT D30A/D70A/D112A, other concentrations were also tested and consistent with this data (Figure S4 in the Supporting Information). 

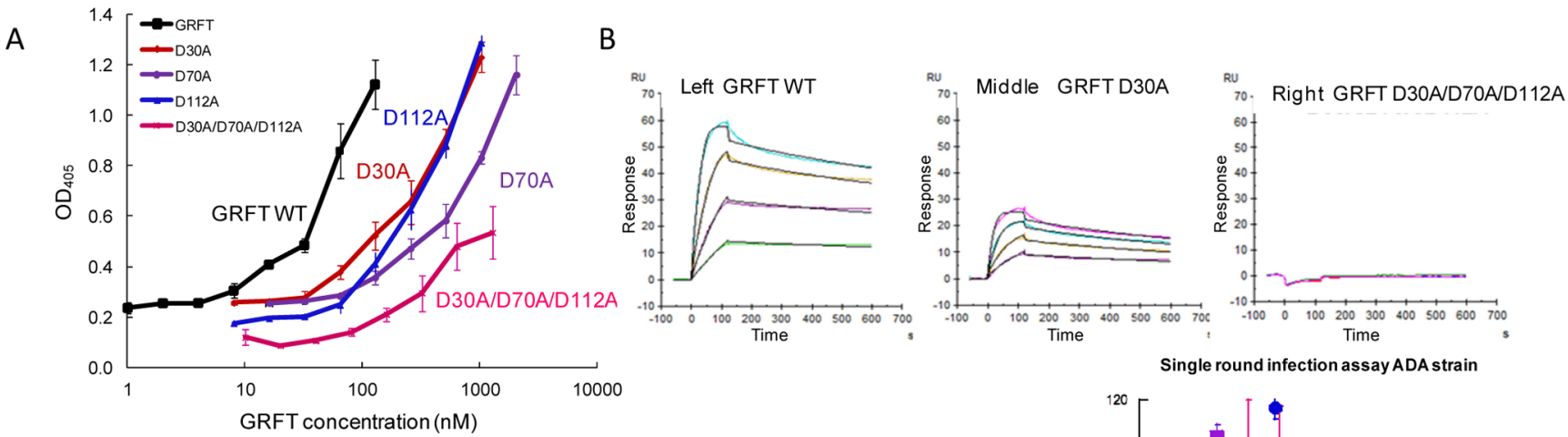

C

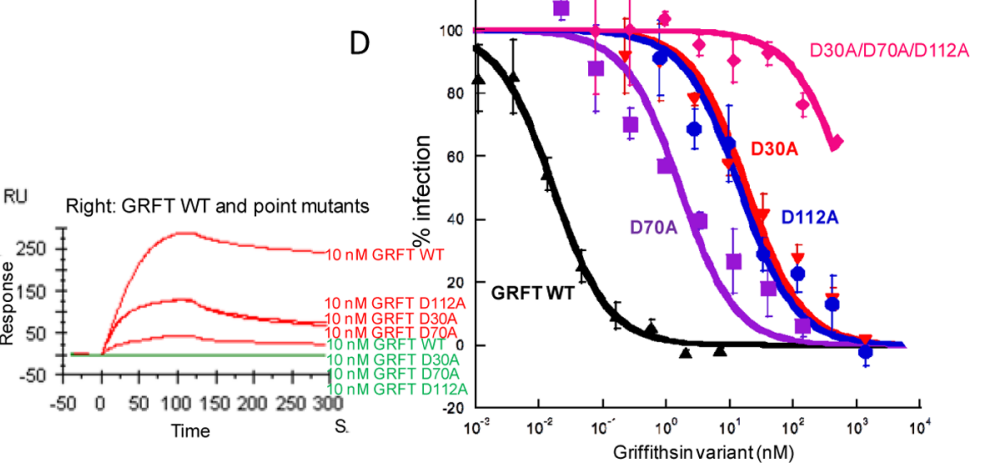

Figure 6. (A) ELISA assay indicates the ability of GRFT and its variants to bind to gp $120_{\mathrm{ADA}}$. Wild-type GRFT (black) binds better than any single point mutant (D30A, red; D70A, purple; D112A, blue). The triple mutation D30A/D70A/D112A (magenta) binds poorly to gp120 ADA $_{\text {. Typical }}$ results are shown from an experiment in triplicate. Each experiment was repeated at least 3 times. Error bars indicate standard deviation from a typical triplicate experiment. (B) Surface plasmon resonance sensorgrams of GRFT binding to gp $120_{\mathrm{ADA}}$ immobilized on the surface. Kinetic analysis of the interactions of GRFT (left panel), GRFT D30A (middle panel) and GRFT triple mutant (right panel) with immobilized HIV-1 ADA gp120. Serial 2-fold analyte dilutions (covering a concentration range from 1.51 to $12.05 \mathrm{nM}$ ) were injected over the surface of the immobilized gp120. The experimental data (colored curves) were fit using the 1:1 binding model (black lines) to determine the kinetic parameters. The biosensor chip density was 90 RU. Concentration shown here is in dimer units. (C) Surface plasmon resonance binding assay of GRFT binding to immobilized glycosylated HIV-1/ $\mathrm{III}_{\mathrm{B}}$ gp120 (expressed in $\mathrm{CHO}$ ) and nonglycosylated HIV-1/ $\mathrm{III}_{\mathrm{B}}$ gp160 (expressed in E. coli). A protein density of $647 \mathrm{RU}$ and $667 \mathrm{RU}$ were obtained for the glycosylated $\mathrm{HIV}-1 / \mathrm{III}_{\mathrm{B}}$ gp 120 and the nonglycosylated $\mathrm{HIV}-1 / \mathrm{III}_{\mathrm{B}}$ gp 160 . Binding signals for the interactions of 10 nM GRFT triple mutant and $200 \mathrm{nM} 2 \mathrm{G} 12$ (left panel); $500 \mathrm{nM} \mathrm{sCD} 4$ and $50 \mathrm{nM}$ HHA (middle panel); and GRFT WT and its single mutants (all at $10 \mathrm{nM}$ ) (right panel) with immobilized glycosylated HIV-1 $\mathrm{II}_{\mathrm{B}}$ gp120 (red curves) and nonglycosylated HIV-1 $\mathrm{III}_{\mathrm{B}}$ gp160 (green curves). (D) Results of inhibition by GRFT mutants in single-round virus assays. Typical results are shown from an experiment in triplicate. Wild-type GRFT is shown in black; D30A, red; D70A, purple; D112A, blue; triple mutation D30A/D70A/D112A, magenta). Each experiment was repeated at least 3 times. Error bars indicate standard deviation from a triplicate experiment.

tested (500 $\mathrm{nM}$ ) against the R5 HIV-1 strains (Figure 6D and Table 3).

The much poorer antiviral activity of the point mutants and the triple GRFT mutant was also confirmed in cocultivation experiments in which the compounds were exposed to a coculture of persistently HIV-1 $\left(\mathrm{III}_{\mathrm{B}}\right)$-infected HuT-78 cells and uninfected Sup T1 CD4+ T-lymphocytes. Whereas the wildtype GRFT potently prevented syncytia formation in the cocultures at an $\mathrm{EC}_{50}$ of $1.91 \pm 1.23 \mathrm{nM}$, the D30A, D70A and D112A point mutants showed $\mathrm{EC}_{50}$ values of $67.4 \pm 39.7 \mathrm{nM}$, $88.6 \pm 23.8 \mathrm{nM}$ and $36.1 \pm 14.3 \mathrm{nM}$, respectively. The triple GRFT mutant was only inhibitory in this assay at $340 \mathrm{nM}$.

GRFT neutralizes HIV-1 by binding to specific N-glycans on HIV-1 gp120 rather than those on cells. Therefore, a preincubation experiment was performed in which MT-4 cells were exposed to GRFT for $1 \mathrm{~h}$ prior to infection of the cell cultures. In these experiments, an increased antiviral (5- to 10fold decreased $\mathrm{EC}_{50}$ ) efficacy of the compound was observed (data not shown). A similar phenomenon was previously also reported for several plant lectins, ${ }^{54}$ and might be important in view of the potential of GRFT as an anti-HIV microbicide drug.

\section{DISCUSSION}

GRFT is a protein lectin that potently inhibits HIV entry and infection by binding to gp $120 .^{3}$ Since its discovery in 2005 , GRFT has been considered a leading candidate for an anti-HIV microbicide, due to its high potency, low toxicity, and good stability to a variety of $\mathrm{pH}$ conditions and temperature. ${ }^{3,11,12}$ This lectin has been shown to be easily produced in gram quantities, leading to the possibility of simple and inexpensive production. ${ }^{10,55}$ It proved also able to inhibit hepatitis $C$ virus infection and dissemination both in vitro and in vivo by acting on the entry step of the viral life cycle. ${ }^{56}$

Several high quality X-ray structures and thermodynamic analyses of GRFT have been carried out, showing a protein dimer and indicating three carbohydrate-binding sites per monomer of protein; ${ }^{4-6,13}$ Figure 4A. Competition data and further structural work ${ }^{3,6}$ indicate that each binding site binds one mannose monosaccharide, which is likely the key to GRFT's ability to inhibit HIV. The HIV envelope protein gp120 contains between 18 and $33 \mathrm{~N}$-linked glycosylation sites (depending on the virus strain), approximately a dozen of which are high-mannose type glycans. ${ }^{57-60}$ These highmannose glycans, in particular their highly clustered appearance on the HIV envelope gp120, are rarely found on mammalian 
cells, reducing the possibility of adverse host interactions ${ }^{61}$ although one study indicates that GRFT can bind to the surface of some cells. ${ }^{12}$ High-mannose glycans contain several branched carbohydrate chains, having three terminal $(\alpha 1,2)$ mannose residues (Figure 1). It is therefore generally assumed that GRFT inhibits viral entry by binding tightly to the mannose on the surface gp120.

Given its relatively high profile and potential for clinical use, it is important that the action of GRFT is biochemically well understood. However, many biochemical details of the role of GRFT in HIV inhibition have not yet been elucidated. For example, while modeling studies suggested three equivalent CBS for each monomer subunit of GRFT, a recent X-ray analysis indicates a subtle lack of equivalence between these sites. ${ }^{4}$ Recent studies have used a GRFT mutant with all three CBS mutated to asparagine, and this mutant GRFT showed no activity in biological assays against several viruses, including Coronaviridae and hepatitis C. ${ }^{12,56,62}$ While this triple Asp-toAsn mutant is likely quite similar to the triple D30A/D70A/ D112A mutant reported here, we do see some minimal activity in $\mathrm{D} 30 \mathrm{~A} / \mathrm{D} 70 \mathrm{~A} / \mathrm{D} 112 \mathrm{~A}$, while none has yet been reported for the triple Asn construct. It appears that our triple mutant retains some weaker binding activity to gp 120 as shown by SPR technology, while these assays were not performed for the triple-Asn mutation. Also, the lack of activity for the triple-Asn mutant was reported for viruses other than HIV, which makes direct comparison to our findings not obvious.

In the present work, we have individually mutated each CBS in GRFT, and analyzed the resulting mutants for their ability to dimerize, to bind to mannose, to bind to gp120, and to inhibit HIV. We found that GRFT and its point mutants form a highaffinity dimer that does not dissociate at the lowest level of detection using analytical ultracentrifugation. Further, while the wild-type protein binds well to a mannose monosaccharide column, mutation at any individual site results in the lack of ability to bind this commercial column. NMR spectroscopy of the wild-type protein in the presence of mannose reveals chemical shift changes across the entire face of the protein containing the mannose binding sites. Single site mutants at each binding site show localized changes in the chemical shifts at those sites, as well as some changes at more distal locations, but generally on the mannose binding face of the protein rather than in more buried residues.

Disruption of any single CBS in GRFT results in a moderate loss of ability to bind HIV gp120 as shown by ELISA. These assays show a reduction in ability to bind gp120 from strain $\mathrm{ADA}$, requiring concentrations about 10 -fold higher from each mutant GRFT compared to the wild-type protein, with the D70A variant appearing to perform several fold worse than $\mathrm{D} 30 \mathrm{~A}$ or D112A. In more quantitative binding assays using SPR, GRFT and its mutants were tested for binding to immobilized gp 120 (from R5 strain ADA and X4 strain $\mathrm{III}_{\mathrm{B}}$ ) as well as to gp41. These experiments showed picomolar binding by wild-type GRFT and only a 2-3-fold reduction in binding by the point mutants $\mathrm{D} 30 \mathrm{~A}, \mathrm{D} 112 \mathrm{~A}$, and $\mathrm{D} 70 \mathrm{~A}$, the latter showing slightly worse binding than the other two mutants.

However, when these mutants were tested in single-round HIV infection assays as well as HIV cytopathicity assays (readout after 4 days) and cocultivation assays ( $24 \mathrm{~h}$ read-out), it was found that their ability to inhibit HIV was much more drastically affected than would be predicted based on their ability to bind gp120 (or gp41). For each virus strain tested, the point mutants showed at least a 26 -fold or higher increase in 
Table 3. Inhibition of GRFT Variants in Single-Round Viral Assays or Antiretroviral Assays ${ }^{a}$

\begin{tabular}{|c|c|c|c|c|c|c|c|c|}
\hline \multirow[b]{3}{*}{ compd } & \multicolumn{8}{|c|}{ inhibition of } \\
\hline & \multicolumn{2}{|c|}{ ADA strain (R5) } & \multicolumn{2}{|c|}{ JR-FL strain (R5) } & \multicolumn{2}{|c|}{ SF 162 strain (R5) } & \multicolumn{2}{|c|}{$\mathrm{III}_{\mathrm{B}}$ strain $(\mathrm{X} 4)$} \\
\hline & $\mathrm{EC}_{50}(\mathrm{nM})$ & $\begin{array}{c}\text { fold } \\
\text { decrease }\end{array}$ & $\mathrm{EC}_{50}(\mathrm{nM})$ & $\begin{array}{c}\text { fold } \\
\text { decrease }\end{array}$ & $\mathrm{EC}_{50}(\mathrm{nM})$ & $\begin{array}{c}\text { fold } \\
\text { decrease }\end{array}$ & $\mathrm{EC}_{50}(\mathrm{nM})$ & $\begin{array}{c}\text { fold } \\
\text { decrease }\end{array}$ \\
\hline GRFT & $0.011 \pm 0.008$ & 1 & $0.073 \pm 0.030$ & 1 & $0.032 \pm 0.015$ & 1 & $0.109 \pm 0.0$ & 1 \\
\hline GRFT D30A & $20 \pm 14$ & 1933 & $23 \pm 23$ & 322 & $13 \pm 2.1$ & 417 & $6.8 \pm 0.6$ & 63 \\
\hline GRFT D70A & $2.6 \pm 2.2$ & 250 & $3.0 \pm 1.7$ & 41 & $0.8 \pm 0.6$ & 26 & $6.7 \pm 2.2$ & 61 \\
\hline GRFT D112A & $6.6 \pm 6.1$ & 625 & $21 \pm 9$ & 284 & $8.7 \pm 3.1$ & 276 & $4.8 \pm 0.5$ & 44 \\
\hline GRFT triple mutant & $>500$ & $>47600$ & $>500$ & $>6900$ & $>500$ & $>15800$ & $95 \pm 33$ & 875 \\
\hline
\end{tabular}

${ }^{a}$ Each experiment was repeated at least 3 times in triplicate, and the values shown are \pm the standard deviation of the EC ${ }_{50}$ from all experiments. The experiments with R5-tropic strains were carried out with TZM-bl target cells. The $\mathrm{EC}_{50}$ determination is described in the Experimental Methods section and is defined as the compound concentration required to inhibit HIV-induced syncytium formation by 50\%. The experiments with X4tropic strain $\mathrm{III}_{\mathrm{B}}$ were carried out with CEM target cells. In this assay system, HIV-induced syncytia formation was examined microscopically at day 4 post infection. "Fold decrease" indicates decrease in potency compared to wild-type GRFT.

$\mathrm{EC}_{50}$ compared to the wild-type protein (although it should be noted that in the context of a dimer, each point mutant results in an overall loss of two CBSs). It was also found that the D70A mutant, while showing lower binding to gp120 in both ELISA and SPR assays, showed better HIV inhibition than the other point mutants in some strains, again indicating a lack of direct correlation between binding to HIV gp120 and viral inhibition.

While the three mannose binding sites of GRFT each use similar amino acid side chains and backbone for carbohydrate binding, a recent crystallography study suggests that two of the sites bind equivalently (pocket 1 , including D112, and pocket 3 , including D70), while the third site binds differently and may have a less optimal binding environment (pocket 2 including D30) ${ }^{4,6}$ notation introduced in refs 4 and 5 . The present work directly investigated each CBS, and our data indicate that the D30 and D112 site are largely identical in terms of contribution to binding of gp120 and inhibition of HIV. The loss of the D70 CBS site appears to have a somewhat different outcome, with consistently better HIV inhibition than the other single mutants. Therefore, the present experiments are not completely in agreement with the previous work, so further experiments may be necessary to resolve this issue.

Our results have implications for the mechanism of action of GRFT. Although mutants lacking one of the three mannose binding sites perform well in binding gp120, all three sites are apparently important for efficient antiviral activity. This strongly implies that GRFT does not function simply by binding gp120 and causing a steric blockade, but rather uses multiple binding interactions with glycans to cause an allosteric shift or a structural shift that inhibits infection by compromising the ability of gp120 to efficiently interact with the host cell during infection. In support of this, recent work has shown that binding of GRFT to gp120 enhances the exposure of the CD4 binding site in gp120, while apparently decreasing the ability of the intact virus to bind the coreceptor. ${ }^{63}$ In fact, it is wellknown from antibody research that binding to gp120 does not guarantee an antiviral effect; binding to gp120 can result in potent neutralization of the virus but may also have poor, if any, effect on viral infectivity, depending on the epitope that is recognized on gp120 by these antibodies. ${ }^{64,65}$ Thus, it seems that the GRFT mutants bind nearly as efficiently to gp120 as wild-type GRFT (as found in our ELISA and SPR experiments) but are not necessarily equally efficiently neutralizing the virus. The efficient capacity of cross-linking of glycans or glycan parts on gp120 by wild-type GRFT may have been markedly decreased by the mutants, explaining the substantially decreased antiviral potential of the mutants versus wild-type protein. Although this hypothesis has still to be proven by direct experimental evidence, these observations suggest that binding as such to gp120 is not necessarily predictive for eventual antiviral activity of the agents and cross-linking of glycans on gp120 may be a key event to efficiently inhibit virus infectivity. The importance of glycan cross-linking for eventual potent antiviral activity by carbohydrate-binding agents has also been suggested earlier by Moulaei et al. ${ }^{4}$ for GRFT, who showed that a monomeric form of the protein is able to bind two different carbohydrate moieties, and also that the monomer itself is not sufficient for anti-HIV function. The possibility of lectin function based on glycan cross-linking has also been raised for cyanovirin- $\mathrm{N}$, which can bind multiple carbohydrates and requires two active sites for its antiviral function. 9,66

The tight GRFT dimer is also likely critical for antiviral function, leading to a total of 6 mannose binding sites. Indeed, as mentioned, an engineered GRFT monomer was recently shown to have low antiviral potency despite retaining binding ability to gp $120{ }^{4}$ We are currently investigating the role of the GRFT dimer in HIV inhibition, where it is possible that the protein uses both arms to alter the conformation of a gp120 subunit or to bind two separate gp120s. The commercially obtained gp120 used in our ELISA and for most SPR experiments is a monomer, while the viral surface contains trimeric gp 120. ${ }^{67,68}$ However, when binding of wild-type GRFT (and its individual point mutants) to trimeric gp140 was compared with monomeric gp120, no significant differences were observed. Nevertheless, these findings leave open the possibility that the antiviral activity of GRFT involves crosslinking of separate gp120 subunits on the virus particle.

\section{CONCLUSIONS}

The potent HIV inhibitor GRFT has been shown to be a tight dimer, with three nearly equivalent mannose binding sites that are each critical for full potency of the anti-HIV activity of the protein. Mutation of any of the three sites results in a loss of at least 26-fold in ability to inhibit HIV, even though these single mutations only moderately affect the ability of GRFT to bind gp120 or gp41. Overall, this suggests that the antiviral mechanism of GRFT action is not simply to bind and sterically block the action of gp120, but rather to use the binding of mannose residues on g120 to affect the gp120 structure or its 
oligomeric state, possibly by cross-linking gp120 glycans, resulting in a loss of viral infectivity.

\section{ASSOCIATED CONTENT}

\section{S Supporting Information}

Additional figures and tables as discussed in the text. This material is available free of charge via the Internet at http:// pubs.acs.org.

\section{AUTHOR INFORMATION}

\section{Corresponding Author}

*University of California Merced, School of Natural Sciences, 5200 N. Lake Rd., Merced, CA 95343. E-mail: pliwang@ ucmerced.edu. Tel: (209) 228-4568. Fax: 209 724-4459.

\section{Present Address}

${ }^{\ddagger}$ Institute of Biochemistry and Cell Biology, Shanghai Institutes for Biological Sciences, Chinese Academy of Sciences, 320 Yueyang Road, Shanghai 200031, China.

\section{Notes}

The authors declare no competing financial interest.

\section{ACKNOWLEDGMENTS}

The authors thank Dr. Andy LiWang and Nicholas Miller for technical assistance. We thank Mr. Virgil Schirf for performing the sedimentation velocity experiments at the Center for Analytical Ultracentrifugation of Macromolecular Assemblies (CAUMA) at the University of Texas Health Science Center at San Antonio. This work was supported by NIH (R21 AI079777), 1P20MD005049-01 from the National Center on Minority Health and Health Disparities and grants from the KU Leuven (PF 10/018; GOA 10/14; G-0528-12N). The UltraScan software development is supported by NIH Grant RR022200 (B.D.). Computations were performed at the Texas Advanced Computing Center of the University of Texas, Austin, on Lonestar and Ranger with support from NSF TeraGrid allocation TG-MCB070039 (B.D.). The technical assistance of Mrs. Leen Ingels for the HIV assays is greatly appreciated. The chemical shifts reported have been deposited into the Biological Magnetic Resonance Data bank Accession 18585.

\section{ABBREVIATIONS USED}

GRFT, griffithsin; CBS, carbohydrate binding site; SPR, surface plasmon resonance; ELISA, enzyme-linked immunosorbent assay; RU, resonance unit; IPTG, isopropyl $\beta$-D-1-thiogalactopyranoside; CPRG, chlorophenol red-D-galactopyranoside; DSS, 2,2-dimethyl-2-silapentane-5-sulfonic acid; SDS-PAGE, sodium dodecyl sulfate polyacrylamide gel electrophoresis

\section{REFERENCES}

(1) Root, M. J.; Steger, H. K. HIV-1 gp41 as a target for viral entry inhibition. Curr. Pharm. Des. 2004, 10 (15), 1805-25.

(2) Gaertner, H.; Cerini, F.; Escola, J. M.; Kuenzi, G.; Melotti, A.; Offord, R.; Rossitto-Borlat, I.; Nedellec, R.; Salkowitz, J.; Gorochov, G.; Mosier, D.; Hartley, O. Highly potent, fully recombinant anti-HIV chemokines: reengineering a low-cost microbicide. Proc. Natl. Acad. Sci. U.S.A. 2008, 105 (46), 17706-11.

(3) Mori, T.; O'Keefe, B. R.; Sowder, R. C., 2nd; Bringans, S.; Gardella, R.; Berg, S.; Cochran, P.; Turpin, J. A.; Buckheit, R. W., Jr.; McMahon, J. B.; Boyd, M. R. Isolation and characterization of griffithsin, a novel HIV-inactivating protein, from the red alga Griffithsia sp. J. Biol. Chem. 2005, 280 (10), 9345-53.
(4) Moulaei, T.; Shenoy, S. R.; Giomarelli, B.; Thomas, C.; McMahon, J. B.; Dauter, Z.; O’Keefe, B. R.; Wlodawer, A. Monomerization of viral entry inhibitor griffithsin elucidates the relationship between multivalent binding to carbohydrates and antiHIV activity. Structure 2010, 18 (9), 1104-15.

(5) Ziolkowska, N. E.; O’Keefe, B. R.; Mori, T.; Zhu, C.; Giomarelli, B.; Vojdani, F.; Palmer, K. E.; McMahon, J. B.; Wlodawer, A. Domainswapped structure of the potent antiviral protein griffithsin and its mode of carbohydrate binding. Structure 2006, 14 (7), 1127-35.

(6) Ziolkowska, N. E.; Shenoy, S. R.; O’Keefe, B. R.; McMahon, J. B.; Palmer, K. E.; Dwek, R. A.; Wormald, M. R.; Wlodawer, A. Crystallographic, thermodynamic, and molecular modeling studies of the mode of binding of oligosaccharides to the potent antiviral protein griffithsin. Proteins 2007, 67 (3), 661-70.

(7) Bewley, C. A. Solution structure of a cyanovirin-N:Man alpha 12Man alpha complex: structural basis for high-affinity carbohydratemediated binding to gp120. Structure 2001, 9 (10), 931-40.

(8) Botos, I.; O’Keefe, B. R.; Shenoy, S. R.; Cartner, L. K.; Ratner, D. M.; Seeberger, P. H.; Boyd, M. R.; Wlodawer, A. Structures of the complexes of a potent anti-HIV protein cyanovirin-N and high mannose oligosaccharides. J. Biol. Chem. 2002, 277 (37), 34336-42.

(9) Shenoy, S. R.; Barrientos, L. G.; Ratner, D. M.; O'Keefe, B. R.; Seeberger, P. H.; Gronenborn, A. M.; Boyd, M. R. Multisite and multivalent binding between cyanovirin- $\mathrm{N}$ and branched oligomannosides: calorimetric and NMR characterization. Chem. Biol. 2002, 9 (10), 1109-18.

(10) O'Keefe, B. R.; Vojdani, F.; Buffa, V.; Shattock, R. J.; Montefiori, D. C.; Bakke, J.; Mirsalis, J.; d'Andrea, A. L.; Hume, S. D.; Bratcher, B.; Saucedo, C. J.; McMahon, J. B.; Pogue, G. P.; Palmer, K. E. Scaleable manufacture of HIV-1 entry inhibitor griffithsin and validation of its safety and efficacy as a topical microbicide component. Proc. Natl. Acad. Sci. U.S.A. 2009, 106 (15), 6099-104.

(11) Emau, P.; Tian, B.; O’Keefe B, R.; Mori, T.; McMahon, J. B.; Palmer, K. E.; Jiang, Y.; Bekele, G.; Tsai, C. C. Griffithsin, a potent HIV entry inhibitor, is an excellent candidate for anti-HIV microbicide. J. Med. Primatol. 2007, 36 (4-5), 244-53.

(12) Kouokam, J. C.; Huskens, D.; Schols, D.; Johannemann, A.; Riedell, S. K.; Walter, W.; Walker, J. M.; Matoba, N.; O’Keefe, B. R.; Palmer, K. E. Investigation of griffithsin's interactions with human cells confirms its outstanding safety and efficacy profile as a microbicide candidate. PLoS One 2011, 6 (8), e22635.

(13) Ziolkowska, N. E.; Shenoy, S. R.; O’Keefe, B. R.; Wlodawer, A. Crystallographic studies of the complexes of antiviral protein griffithsin with glucose and $\mathrm{N}$-acetylglucosamine. Protein Sci. 2007, 16 (7), 1485-9.

(14) Alexandre, K. B.; Gray, E. S.; Lambson, B. E.; Moore, P. L.; Choge, I. A.; Mlisana, K.; Karim, S. S.; McMahon, J.; O’Keefe, B.; Chikwamba, R.; Morris, L. Mannose-rich glycosylation patterns on HIV-1 subtype C gp120 and sensitivity to the lectins, Griffithsin, Cyanovirin-N and Scytovirin. Virology 2010, 402 (1), 187-96.

(15) Alexandre, K. B.; Gray, E. S.; Mufhandu, H.; McMahon, J. B.; Chakauya, E.; O'Keefe, B. R.; Chikwamba, R.; Morris, L. The lectins griffithsin, cyanovirin-N and scytovirin inhibit HIV-1 binding to the DC-SIGN receptor and transfer to CD4(+) cells. Virology 2012, 423 (2), $175-86$

(16) Huang, X.; Jin, W.; Griffin, G. E.; Shattock, R. J.; Hu, Q. Removal of two high-mannose $\mathrm{N}$-linked glycans on gp120 renders human immunodeficiency virus 1 largely resistant to the carbohydratebinding agent griffithsin. J. Gen. Virol. 2011, 92 (Part 10), 2367-73.

(17) Boyd, M. R.; Gustafson, K. R.; McMahon, J. B.; Shoemaker, R. H.; O’Keefe, B. R.; Mori, T.; Gulakowski, R. J.; Wu, L.; Rivera, M. I.; Laurencot, C. M.; Currens, M. J.; Cardellina, J. H., 2nd; Buckheit, R. W., Jr.; Nara, P. L.; Pannell, L. K.; Sowder, R. C., 2nd; Henderson, L. E. Discovery of cyanovirin-N, a novel human immunodeficiency virusinactivating protein that binds viral surface envelope glycoprotein gp120: potential applications to microbicide development. Antimicrob. Agents Chemother. 1997, 41 (7), 1521-30.

(18) Gendelman, H. E.; Baca, L. M.; Kubrak, C. A.; Genis, P.; Burrous, S.; Friedman, R. M.; Jacobs, D.; Meltzer, M. S. Induction of 
IFN-alpha in peripheral blood mononuclear cells by HIV-infected monocytes. Restricted antiviral activity of the HIV-induced IFN. J. Immunol. 1992, 148 (2), 422-9.

(19) Gendelman, H. E.; Orenstein, J. M.; Baca, L. M.; Weiser, B.; Burger, H.; Kalter, D. C.; Meltzer, M. S. The macrophage in the persistence and pathogenesis of HIV infection. AIDS 1989, 3 (8), 475-95.

(20) Gendelman, H. E.; Orenstein, J. M.; Martin, M. A.; Ferrua, C.; Mitra, R.; Phipps, T.; Wahl, L. A.; Lane, H. C.; Fauci, A. S.; Burke, D. S.; et al. Efficient isolation and propagation of human immunodeficiency virus on recombinant colony-stimulating factor 1-treated monocytes. J. Exp. Med. 1988, 167 (4), 1428-41.

(21) Westervelt, P.; Gendelman, H. E.; Ratner, L. Identification of a determinant within the human immunodeficiency virus 1 surface envelope glycoprotein critical for productive infection of primary monocytes. Proc. Natl. Acad. Sci. U.S.A. 1991, 88 (8), 3097-101.

(22) Connor, R. I.; Chen, B. K.; Choe, S.; Landau, N. R. Vpr is required for efficient replication of human immunodeficiency virus type-1 in mononuclear phagocytes. Virology 1995, 206 (2), 935-44.

(23) Cheng-Mayer, C.; Liu, R.; Landau, N. R.; Stamatatos, L. Macrophage tropism of human immunodeficiency virus type 1 and utilization of the CC-CKR5 coreceptor. J. Virol. 1997, 71 (2), 165761.

(24) Stamatatos, L.; Lim, M.; Cheng-Mayer, C. Generation and structural analysis of soluble oligomeric gp140 envelope proteins derived from neutralization-resistant and neutralization-susceptible primary HIV type 1 isolates. AIDS Res. Hum. Retroviruses 2000, 16 (10), 981-94.

(25) Stamatatos, L.; Wiskerchen, M.; Cheng-Mayer, C. Effect of major deletions in the V1 and V2 loops of a macrophage-tropic HIV type 1 isolate on viral envelope structure, cell entry, and replication. AIDS Res. Hum. Retroviruses 1998, 14 (13), 1129-39.

(26) Bax, A. Triple resonance three-dimensional protein NMR: before it became a black box. J. Magn. Reson. 2011, 213 (2), 442-5.

(27) Bax, A.; Grzesiek, S. Methodological advances in protein NMR. Acc. Chem. Res. 1993, 26, 131-8.

(28) Grzesiek, S.; Bax, A. An efficient experiment for sequential backbone assignment of medium-sized isotopically enriched proteins. J. Magn. Reson. 1992, 99, 201-7.

(29) Grzesiek, S.; Bax, A. Correlating backbone amide and side chain resonances in larger proteins by multiple relayed triple resonance NMR. J. Am. Chem. Soc. 1992, 114, 6291-3.

(30) Delaglio, F.; Grzesiek, S.; Vuister, G. W.; Hu, G.; Pfeifer, J.; Bax, A. NMRPipe: A multidimensional spectral processing system based on UNIX pipes. J. Biomol. NMR 1995, 6, 277-93.

(31) Garrett, D. S.; Powers, R.; Gronenborn, A. M.; Clore, G. M. A common sense approach to peak picking in two-, three-, and fourdimensional spectra using automatic computer analysis of contour diagrams. J. Magn. Reson. 1991, 95, 214-20.

(32) Goddard, T. D. D. G. Kneller. Sparky 3. Available from: http:// www.cgl.ucsf.edu/home/sparky/.

(33) Johnson, B. A. Using NMRView to visualize and analyze the NMR spectra of macromolecules. In Methods in molecular biology; Humana Press: Totowa, NJ, 2004; pp 313-52.

(34) Pettersen, E. F.; Goddard, T. D.; Huang, C. C.; Couch, G. S.; Greenblatt, D. M.; Meng, E. C.; Ferrin, T. E. UCSF Chimera-a visualization system for exploratory research and analysis. J. Comput. Chem. 2004, 25 (13), 1605-12.

(35) Garrett, D. S.; Seok, Y. J.; Peterkofsky, A.; Clore, G. M.; Gronenborn, A. M. Identification by NMR of the binding surface for the histidine-containing phosphocarrier protein HPr on the N-terminal domain of enzyme I of the Escherichia coli phosphotransferase system. Biochemistry 1997, 36 (15), 4393-8.

(36) Zhang, L.; Derider, M.; McCornack, M.; Jao, S.-C.; Isern, N.; Ness, T.; Moyer, R.; LiWang, P. Solution structure of the complex between poxvirus-encoded CC chemokine inhibitor vCCI and human MIP-1beta. Proc. Natl. Acad. Sci. U.S.A. 2006, 103, 13985-90.
(37) Zhao, B.; LiWang, P. J. Characterization of the interactions of vMIP-II, and a dimeric variant of vMIP-II, with glycosaminoglycans. Biochemistry 2010, 49 (33), 7012-22.

(38) Eggink, D.; Melchers, M.; Wuhrer, M.; van Montfort, T.; Dey, A. K.; Naaijkens, B. A.; David, K. B.; Le Douce, V.; Deelder, A. M.; Kang, K.; Olson, W. C.; Berkhout, B.; Hokke, C. H.; Moore, J. P.; Sanders, R. W. Lack of complex N-glycans on HIV-1 envelope glycoproteins preserves protein conformation and entry function. Virology 2010, 401 (2), 236-47.

(39) Demeler, B. UltraScan version 9.9: A comprehensive data analysis software package for analytical ultracentrifugation experiments; 2011. Available from: http://www.ultrascan.uthscsa.edu/.

(40) Demeler, B. UltraScan: A Comprehensive Data Analysis Software Package for Analytical Ultracentrifugation Experiments. In Modern Analytical Ultracentrifugation: Techniques and Methods; Scott, D., Harding, S., Rowe, A., Eds.; Royal Society of Chemistry: Cambridge, UK, 2005; pp 210-29.

(41) Brookes, E.; Demeler, B. Parallel computational techniques for the analysis of sedimentation velocity experiments in UltraScan. Colloid Polym. Sci. 2008, 286 (2), 139-48.

(42) Brookes, E.; Cao, W. M.; Demeler, B. A two-dimensional spectrum analysis for sedimentation velocity experiments of mixtures with heterogeneity in molecular weight and shape. Eur. Biophys. J. Biophys. Lett. 2010, 39 (3), 405-14.

(43) Brookes, E.; Boppana, R. V.; Demeler, B. Computing Large Sparse Multivariate Optimization Problems with an Application in Biophysics. Supercomputing '06 ACM 0-7695-2700-0/06 2006, Article No. 81 .

(44) Demeler, B.; van Holde, K. E. Sedimentation velocity analysis of highly heterogeneous systems. Anal. Biochem. 2004, 335 (2), 279-88.

(45) Brookes, E. H.; Demeler, B. Parsimonious Regularization using Genetic Algorithms Applied to the Analysis of Analytical Ultracentrifugation Experiments. Gecco 2007: Genetic and Evolutionary Computation Conference, Vol 1 and 2 2007, 361-8.

(46) Brookes, E.; Demeler, B. Genetic algorithm optimization for obtaining accurate molecular weight distributions from sedimentation velocity experiments. Anal. Ultracentrifugation VIII 2006, 131, 33-40.

(47) Demeler, B.; Brookes, E. Monte Carlo analysis of sedimentation experiments. Colloid Polym. Sci. 2008, 286 (2), 129-37.

(48) Kagiampakis, I.; Gharibi, A.; Mankowski, M. K.; Snyder, B. A.; Ptak, R. G.; Alatas, K.; LiWang, P. J. Potent strategy to inhibit HIV-1 by binding both gp120 and gp41. Antimicrob. Agents Chemother. 2011, 55 (1), 264-75.

(49) Demeler, B.; Saber, H.; Hansen, J. C. Identification and interpretation of complexity in sedimentation velocity boundaries. Biophys. J. 1997, 72 (1), 397-407.

(50) Hoorelbeke, B.; Huskens, D.; Ferir, G.; Francois, K. O.; Takahashi, A.; Van Laethem, K.; Schols, D.; Tanaka, H.; Balzarini, J. Actinohivin, a broadly neutralizing prokaryotic lectin, inhibits HIV-1 infection by specifically targeting high-mannose-type glycans on the gp120 envelope. Antimicrob. Agents Chemother. 2010, 54 (8), 3287301.

(51) Hoorelbeke, B.; Van Damme, E. J.; Rouge, P.; Schols, D.; Van Laethem, K.; Fouquaert, E.; Balzarini, J. Differences in the mannose oligomer specificities of the closely related lectins from Galanthus nivalis and Zea mays strongly determine their eventual anti-HIV activity. Retrovirology 2011, 8 (1), 10.

(52) Furuta, R. A.; Wild, C. T.; Weng, Y.; Weiss, C. D. Capture of an early fusion-active conformation of HIV-1 gp41 [Erratum appears in Nat. Struct. Biol. 19985 (7), 612]. Nat. Struct. Biol. 1998, 5 (4), 2769.

(53) Reeves, J. D.; Gallo, S. A.; Ahmad, N.; Miamidian, J. L.; Harvey, P. E.; Sharron, M.; Pohlmann, S.; Sfakianos, J. N.; Derdeyn, C. A.; Blumenthal, R.; Hunter, E.; Doms, R. W. Sensitivity of HIV-1 to entry inhibitors correlates with envelope/coreceptor affinity, receptor density, and fusion kinetics. Proc. Natl. Acad. Sci. U.S.A. 2002, 99 (25), 16249-54.

(54) Balzarini, J.; Hatse, S.; Vermeire, K.; Princen, K.; Aquaro, S.; Perno, C. F.; De Clercq, E.; Egberink, H.; Vanden Mooter, G.; 
Peumans, W.; Van Damme, E.; Schols, D. Mannose-specific plant lectins from the Amaryllidaceae family qualify as efficient microbicides for prevention of human immunodeficiency virus infection. Antimicrob. Agents Chemother. 2004, 48 (10), 3858-70.

(55) Zeitlin, L.; Pauly, M.; Whaley, K. J. Second-generation HIV microbicides: continued development of griffithsin. Proc. Natl. Acad. Sci. U.S.A. 2009, 106 (15), 6029-30.

(56) Meuleman, P.; Albecka, A.; Belouzard, S.; Vercauteren, K.; Verhoye, L.; Wychowski, C.; Leroux-Roels, G.; Palmer, K. E.; Dubuisson, J. Griffithsin has antiviral activity against hepatitis C virus. Antimicrob. Agents Chemother. 2011, 55 (11), 5159-67.

(57) Leonard, C. K.; Spellman, M. W.; Riddle, L.; Harris, R. J.; Thomas, J. N.; Gregory, T. J. Assignment of intrachain disulfide bonds and characterization of potential glycosylation sites of the type 1 recombinant human immunodeficiency virus envelope glycoprotein (gp120) expressed in Chinese hamster ovary cells. J. Biol. Chem. 1990, 265 (18), 10373-82.

(58) Zhang, M.; Gaschen, B.; Blay, W.; Foley, B.; Haigwood, N.; Kuiken, C.; Korber, B. Tracking global patterns of N-linked glycosylation site variation in highly variable viral glycoproteins: HIV, SIV, and HCV envelopes and influenza hemagglutinin. Glycobiology 2004, 14 (12), 1229-46.

(59) Zhu, X.; Borchers, C.; Bienstock, R. J.; Tomer, K. B. Mass spectrometric characterization of the glycosylation pattern of HIVgp120 expressed in CHO cells. Biochemistry 2000, 39 (37), 11194204.

(60) Doores, K. J.; Bonomelli, C.; Harvey, D. J.; Vasiljevic, S.; Dwek, R. A.; Burton, D. R.; Crispin, M.; Scanlan, C. N. Envelope glycans of immunodeficiency virions are almost entirely oligomannose antigens. Proc. Natl. Acad. Sci. U.S.A. 2010, 107 (31), 13800-5.

(61) Balzarini, J. Targeting the glycans of glycoproteins: a novel paradigm for antiviral therapy. Nat. Rev. Microbiol. 2007, 5 (8), 58397.

(62) O’Keefe, B. R.; Giomarelli, B.; Barnard, D. L.; Shenoy, S. R.; Chan, P. K.; McMahon, J. B.; Palmer, K. E.; Barnett, B. W.; Meyerholz, D. K.; Wohlford-Lenane, C. L.; McCray, P. B., Jr. Broad-spectrum in vitro activity and in vivo efficacy of the antiviral protein griffithsin against emerging viruses of the family Coronaviridae. J. Virol. 2010, 84 (5), 2511-21.

(63) Alexandre, K. B.; Gray, E. S.; Pantophlet, R.; Moore, P. L.; McMahon, J. B.; Chakauya, E.; O’Keefe, B. R.; Chikwamba, R.; Morris, L. Binding of the mannose-specific lectin, griffithsin, to HIV-1 gp120 exposes the CD4-binding site. J. Virol. 2011, 85 (17), 9039-50.

(64) Pejchal, R.; Doores, K. J.; Walker, L. M.; Khayat, R.; Huang, P. S.; Wang, S. K.; Stanfield, R. L.; Julien, J. P.; Ramos, A.; Crispin, M.; Depetris, R.; Katpally, U.; Marozsan, A.; Cupo, A.; Maloveste, S.; Liu, Y.; McBride, R.; Ito, Y.; Sanders, R. W.; Ogohara, C.; Paulson, J. C.; Feizi, T.; Scanlan, C. N.; Wong, C. H.; Moore, J. P.; Olson, W. C.; Ward, A. B.; Poignard, P.; Schief, W. R.; Burton, D. R.; Wilson, I. A. A potent and broad neutralizing antibody recognizes and penetrates the HIV glycan shield. Science 2011, 334 (6059), 1097-103.

(65) Walker, L. M.; Huber, M.; Doores, K. J.; Falkowska, E.; Pejchal, R.; Julien, J. P.; Wang, S. K.; Ramos, A.; Chan-Hui, P. Y.; Moyle, M.; Mitcham, J. L.; Hammond, P. W.; Olsen, O. A.; Phung, P.; Fling, S.; Wong, C. H.; Phogat, S.; Wrin, T.; Simek, M. D.; Koff, W. C.; Wilson, I. A.; Burton, D. R.; Poignard, P. Broad neutralization coverage of HIV by multiple highly potent antibodies. Nature 2011, 477 (7365), 46670.

(66) Matei, E.; Zheng, A.; Furey, W.; Rose, J.; Aiken, C.; Gronenborn, A. M. Anti-HIV activity of defective cyanovirin-N mutants is restored by dimerization. J. Biol. Chem. 2010, 285 (17), 13057-65.

(67) Harris, A.; Borgnia, M. J.; Shi, D.; Bartesaghi, A.; He, H.; Pejchal, R.; Kang, Y. K.; Depetris, R.; Marozsan, A. J.; Sanders, R. W.; Klasse, P. J.; Milne, J. L.; Wilson, I. A.; Olson, W. C.; Moore, J. P.; Subramaniam, S. Trimeric HIV-1 glycoprotein gp140 immunogens and native HIV-1 envelope glycoproteins display the same closed and open quaternary molecular architectures. Proc. Natl. Acad. Sci. U.S.A. 2011, 108 (28), 11440-5.
(68) Moscoso, C. G.; Sun, Y.; Poon, S.; Xing, L.; Kan, E.; Martin, L.; Green, D.; Lin, F.; Vahlne, A. G.; Barnett, S.; Srivastava, I.; Cheng, R. H. Quaternary structures of HIV Env immunogen exhibit conformational vicissitudes and interface diminution elicited by ligand binding. Proc. Natl. Acad. Sci. U.S.A. 2011, 108 (15), 6091-6. 